\title{
Plasmalipoproteine bei Patienten mit Hyperthyreose: Isolierung und Charakterisierung eines abnormen High-Density-Lipoproteins
}

\author{
Von H. WIELAND und D. SeIDEL \\ Med. Univ. Klinik (Ludolf-Krebl-Klinik) Heidelberg (Direktor Prof. Dr. G. Scbettler)
}

(Eingegangen am 29. Dezember 1971)

\begin{abstract}
Normalerweise finden sich in der HDL-Fraktion ${ }^{1}$ ) nur Lipoproteine mit $\alpha$-Mobilität, während die der LDL- und VLDL-Fraktion als $\beta$ - bzw. prä- $\beta$-Lipoproteine wandern. In der vorliegenden Arbeit wird der Nachweis erbracht, daß in der HDL-Fraktion von Patienten mit Hyperthyreose nicht nur $\alpha$-Lipoproteine, sondern auch solche mit $\beta$-Mobilität in hoher Konzentration vorhanden sind. Diese abnorme Lipoproteinfraktion wird als $\beta$-HDL bezeichnet und kann durch eine Kombination von Ultrazentrifugation und Polyanionenpräzipitation isoliert werden. Im Vergleich zu den normalen $\beta$-Lipoproteinen unterscheidet sich das $\beta$-HDI, in seiner Protein-LipidZusammensetzung, die durch einen hohen Gehalt an Protein und nicdrigen Gehalt an Cholesterin charakterisiert ist. Darüber hinaus sind die $\beta$-HDL-Partikel deutlich kleiner als die normalen $\beta$-Lipoproteine. Die VLDL-, LDL- und $\alpha$-HDL-Fraktion zeigen eine normale ProteinLipid-Zusammensetzung und entwickeln eine normale clektrophoretische Mobilität. Durch immunologische Methoden wird eine Identität zwischen normalen $\beta$-Lipoproteinen und dem $\beta$-HDL bewiesen und gleichzeitig eine Verwandtschaft zwischen dem $\beta$-HDL und dem $\mathrm{L}_{\mathrm{P}}$ (a) Lipoprotein ausgeschlossen. Die genaue Analyse des Proteinanteils des $\beta$-HDL zeigt klar die Beteiligung eines zweiten Proteins neben dem Apo B am Aufbau des HDL-Moleküls. Das zweitc, als $\mathrm{H}_{1}$ bezeichnete Protein unterscheidet sich aufgrund einer eingehenden immunologischen Charakteristik, seiner Aminosäurezusammensetzung sowie in seiner $\mathrm{N}$-terminalen Aminosäure deutlich von allen bekannten Apolipoproteinen und bis heute identifizierten Plasmaproteinen. Das $\mathrm{H}_{1}$ scheint im Kern des $\beta$-HDL Moleküls lokalisiert zu sein. Die Ergebnisse von Lipidbindungsversuchen in vitro lassen darauf schließen, daß die abnorme Protein-Lipid-Zusammensetzung des $\beta$-HDL eher durch die spezifische Kombination des Apo B mit dem $\mathrm{H}_{1}$-Protein bestimmt wird, als durch das Lipidangebot. Da sich das $\beta$-HDL im Plasma gesunder Kontrollpersonen nie nachweisen läßt, ist es denkbar, daß die Bestimmung des $\beta$-HDL zu einem neuen wertvollen klinisch-chemischen Test in der Differentialdiagnose der Hyperthyreose werden kann. Unter einer erfolgreichen Therapie sinkt die Konzentration des $\beta$-HDL im Plasma von Patienten mit Hyperthyreose; nach optimaler Einstellung der Patienten ist es nicht mehr nachzuweisen.
\end{abstract}

Plasma lipoproteins in patients with bypertbyroidism. Isolation and characterization of an abnormal bigh density lipoprotein The HDL fraction of the serum lipoproteins usually consists exclusively of $\alpha$-lipoproteins, whereas the LDL and VLDL fractions migrate as $\beta$ - and pre $\beta$-lipoproteins, respectively. In the present work, it was found that the HDL fraction from patients with hyperthyroidism also contains a high concentration of lipoproteins with $\beta$-mobility. This abnormal lipoprotein fraction, which is designated $\beta$-HDL, can be isolated by ultracentrifugation and polyanion precipitation. Compared with the normal $\beta$-lipoproteins, the $\beta$-HDL contains a higher concentration of protein and a lower concentration of cholesterol. The $\beta$-HDL particles are also smaller than those of normal $\beta$-lipoproteins. The VLDL, LDL and $\alpha$-HDL fractions from the same patients showed a normal protein - lipid composition and normal electrophoretic mobility. $\beta$-Lipoproteins and $\beta$-HDL were found to be immunologically similar, but there was no immunological relationship between $\beta$-HDL and the $\mathrm{LP}$ (a) factor. However, careful analysis of the protein moiety of $\beta$-HDL indicated the presence of a second protein (designated $\mathrm{H}_{1}$ ) in addition to apolipoprotein $\mathrm{B}$. The protein $\mathrm{H}_{1}$, which is probably in the core of the particle, was characterized immunologically, by amino acid analysis and by its $\mathrm{N}$-terminal amino acid. It differs from all known apolipoproteins and all the plasma proteins so far identified. Studies on the combination with lipids in vitro suggest that the abnormal protein - lipid composition of $\beta$-HDL is determined by the specific combination of apo $\mathrm{B}$ and $\mathrm{H}_{1}$ in the described plasmalipoprotein. The determination of $\beta$-HDL may be useful for the diagnosis of hyperthyroidism. Plasma $\beta$-HDL is no longer demonstrable, following the successful treatment of hyperthyroidism.

\section{Einleitung}

Neben Albumin und den $\gamma$-Globulinen stellen die Lipoproteine die drittstärkste Fraktion der extrazellulären Makromoleküle im Plasma des Menschen dar. Thre Struktur und Funktion hat in der letzten Dekade ein wachsendes Interesse gefunden und die Dynamik ihres Stoffwechsels beginnt sich zu klären.

Der regulierende Einfluß der Schilddrüsenhormone, insbesondere des Thyroxins, auf den Cholesterinstoffwechsel ist seit über 50 Jahren bekannt (1) und in einer Vielzahl von Studien untersucht worden $(1-8)$. Man weiß heute, daß Schilddrüsenhormone die Syntheserate des Cholesterins in der Leber stimulieren (7), aber

1) $\mathrm{HDL}=$ High Density Lipoproteins $\mathrm{LDL}=$ Low Density Lipoproteins; VLDL $=$ Very Low Density Lipoproteins. den Aufbau und die Ausscheidung des Cholesterins durch die Galle noch stärker positiv beeinflussen (8). Dies hat zur Folge, da $\mathrm{A}$ es bei einer Schilddrüsenunterfunktion zu einem Anstieg, bei der Hyperthyreose zu einem Abfall der Plasmacholesterinkonzentration kommt. Diese Prozesse laufen wahrscheinlich unabhängig von dem gleichzeitig bestehenden Hypo- bzw. Hypermetabolismus bei der Hypo- bzw. Hyperthyreose $\mathrm{ab}$, da die Plasmacholesterinspiegel keine eindeutige Beziehung zum Grundumsatz zeigen (8). Die Aktivierung des Stoffwechsels des Fettgewebes und der Triglyceride durch die Schilddrüsenhormone geht nicht nur aus dem Fettschwund bei der Hyperthyreose hervor, sondern zeigt sich vor allem in den nicdrigen respiratorischen Quotienten, der Neigung zur Ketoacidose und auch in der gesteigerten Utilisation der 
Fettsäuren bei der Hyperthyreose (8-11). Analog dem Cholesterinstoffwechsel, wenn auch nicht so ausgeprägt, läßt sich auch im Stoffwechsel der Triglyceride zumindest bei hyperthyreoten Tieren eine erhöhte Synthese $(12,13)$, aber noch stärker ein beschleunigter Abbau nachweisen, wahrscheinlich bedingt durch das gesteigerte Kalorienbedürfnis der Gewebe bei erschöpftem Glucoseangebot $(8,14)$. Die Wirkung der Schilddrüsenhormone auf den Phospholipidstoffwechsel ist bisher kaum untersucht worden und ohne daß hier klare Beziehungen erkannt sind, kann sicher gesagt werden, daß die Hyperthyreose zu keiner signifikanten Senkung der Phospholipidkonzentration im Plasma führt.

Dieser Befund, wie die Tatsache, daß Patienten mit Hyperthyreose trotz niedriger Plasmacholesterinwerte ein normales Lipidelektropherogramm zeigen (vgl. Abb. 1), veranlaßte uns, den Transportmechanismus der Plasmalipide bei der Hyperthyreose genauer zu analysieren.

Die Gründe hierfür liegen in der Kenntnis, daß es bei einem ungestörten Transport der Plasmalipide undenkbar ist, daß der Cholesterinspiegel im Plasma bei gleichbleibenden Phospholipidkonzentrationen absinkt, ohne von einer Verminderung der cholesterinreichen $\beta$ Lipoproteine begleitet zu sein. Dies ist unter physiologischen Bedingungen und normalen Transportverhältnissen dadurch bedingt, daß die wasserunlöslichen Plasmalipide nicht frei im Plasma zirkulieren, sondern transportiert werden, indem sie nach einer ganz bestimmten Ordnung aller Plasmalipide in festen Konzentrationsverhältnissen und wohl strukturiert Verbindungen mit besonderen Proteinen eingehen. Wir bezeichnen diese konjugierten Makromoleküle heute als lösliche oder Plasmalipoproteine im Gegensatz zu den Struktur- oder Membranlipoproteinen. Ihnen kommt, wie die Ergebnisse der Lipidforschung der letzten Jahre vielfältig gezeigt haben und wie durch die Resultate der vorliegenden Arbeit bestätigt wird, eine zentrale Bedeutung bei der Differenzierung und in der

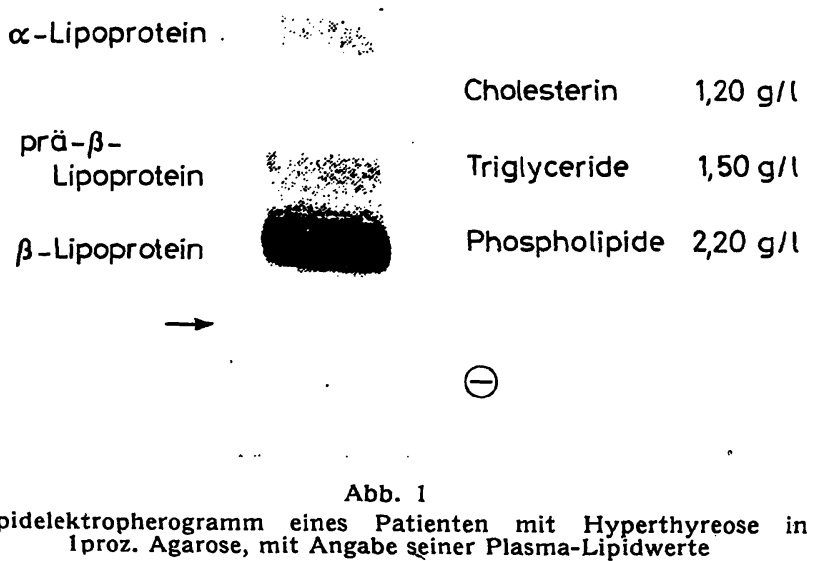

Suche nach den pathophysiologischen Zusammenhängen der Dyslipoproteinämien zu.

\section{Biochemische Charakteristik der normalen Lipoproteinfraktionen (15)}

Die physikochemischen und chemischen Eigenschaften der Plasmalipoproteine, wie ihre Dichte, Größe und elektrophoretische Mobilität sind festgelegt durch ihre konstante ProteinLipid-Zusammensetzung (vgl. Tab. 1). D/a bekanntlich die Lipide eine wesentlich niedrigere Dichte besitzen als die Proteine, zeichnen sich alle Plasmalipoproteine durch eine, verglichen mit den Plasmaproteinen, niedrigere Dichte aus. Das Plasmalipoproteinspektrum erstreckt sich über den Dichtebereich von 0,9 bis $1,21 \mathrm{~g} / \mathrm{ml}$. Die Plasmalipoproteine mit sehr niedriger Dichte bestehen vorwiegend aus Triglyceriden und sind die größten Lipoproteine, während mit höherer Dichte ihre Größe ab und ihr Proteingehalt zunimmt. Sie alle setzen sich jedoch aus den 4 Komponenten Protein, Cholesterin, Triglycerid und Phospholipid zusammen, allerdings zu unterschiedlichen, aber normalerweise sehr konstanten Konzentrationsverhältnissen. Untersucht man das Plasmalipoproteinspektrum in der analytischen Ultrazentrifuge, so zeigen sich vier immer wiederkehrende Konzentrationsmaxima und -minima. Die Konzentrationsminima gelten als Grenzdichten zur Fraktionierung der Plasmalipoproteine nach Dichteklassen mit Hilfe der präparativen Ultrazentrifuge. Mit ihr lassen sich die Plasmalipoproteine in prinzipiell vier Klassen fraktionieren:

Tạb. 1

Charakteristik der normalen Plasmalipoproteine a) Physiko-chemische Eigenschaften

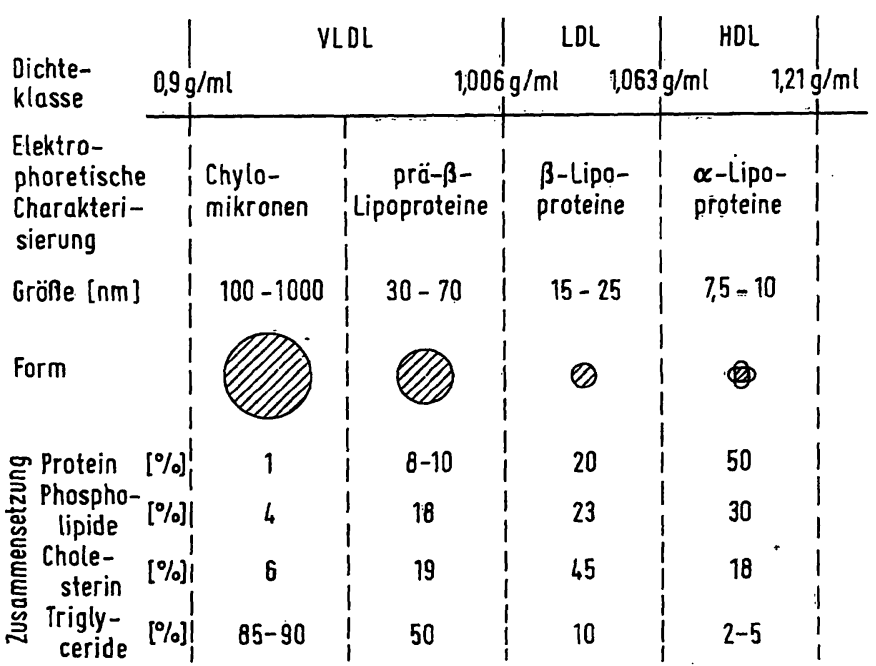

b) Verteilung der Apolipoproteine

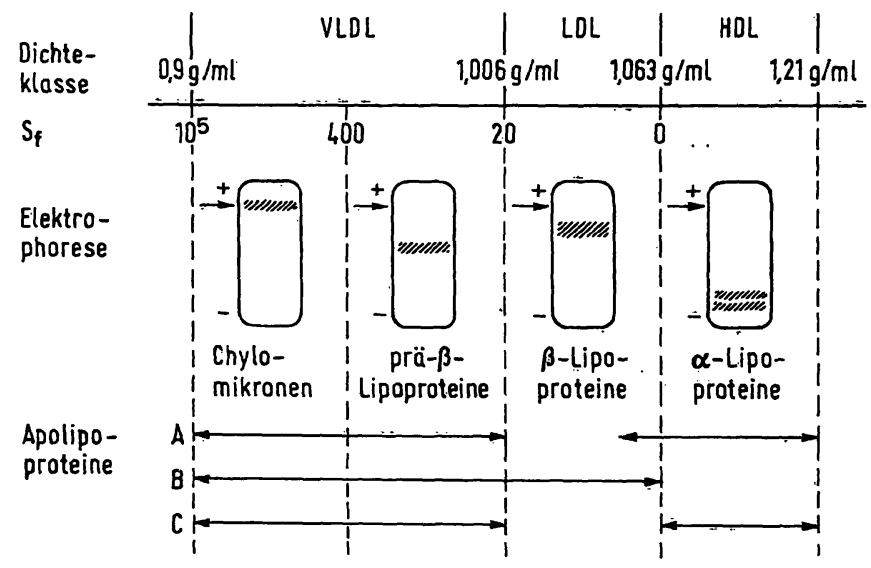




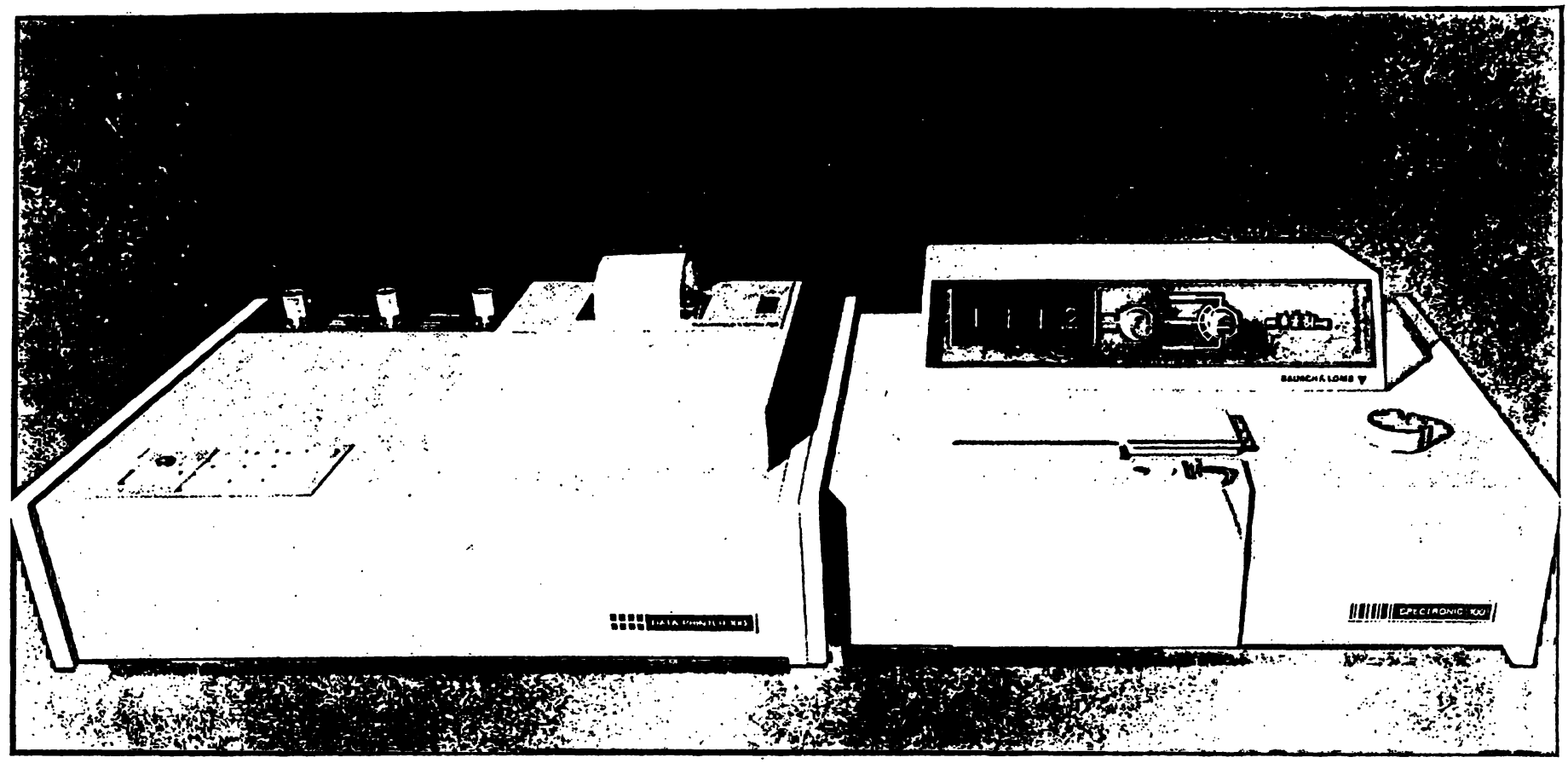

\section{Spectronic ${ }^{\circledast}$ System 400-2 von BAUSCH \& LOMB}

\section{Ein programmgestenenter MeBplatz fuir Endpunkto unmd kimetische Bestimmmungem}

Das Spektralphotometer dieses Meß- $\quad$ Dieser Meßplatz bietet sich für Serienplatzes ist das bewährte SPECTRONIC 100 messungen förmlich an. Die manuelle oder mit digitaler Meßwertanzeige im Wellen- automatische Probenzuführung startet den längenbereich $325-925 \mathrm{~nm}$. Ablauf des gesamten Meßvorganges und der Datenprotokollierung.

口 Am Steuergerät DP 100 wird der Keine Ablesefehler mehr, keine zeitMeßablauf programmiert und die am Photo- raubende Meßwertübertragung, geringste meter angezeigten Meßwerte in T, E oder Verschleppungsfehler, höchstmögliche $\mathrm{C}$ mit Proben-Identifizierung ausgedruckt. Meßfrequenz.

Verkauf und Service durch die technischen Büros der BAUSCH \& LOMB-Organisation

\section{BAUSCH \& LOMB ( $\mathrm{GMBH}$}

ANALYSENSYSTEME 


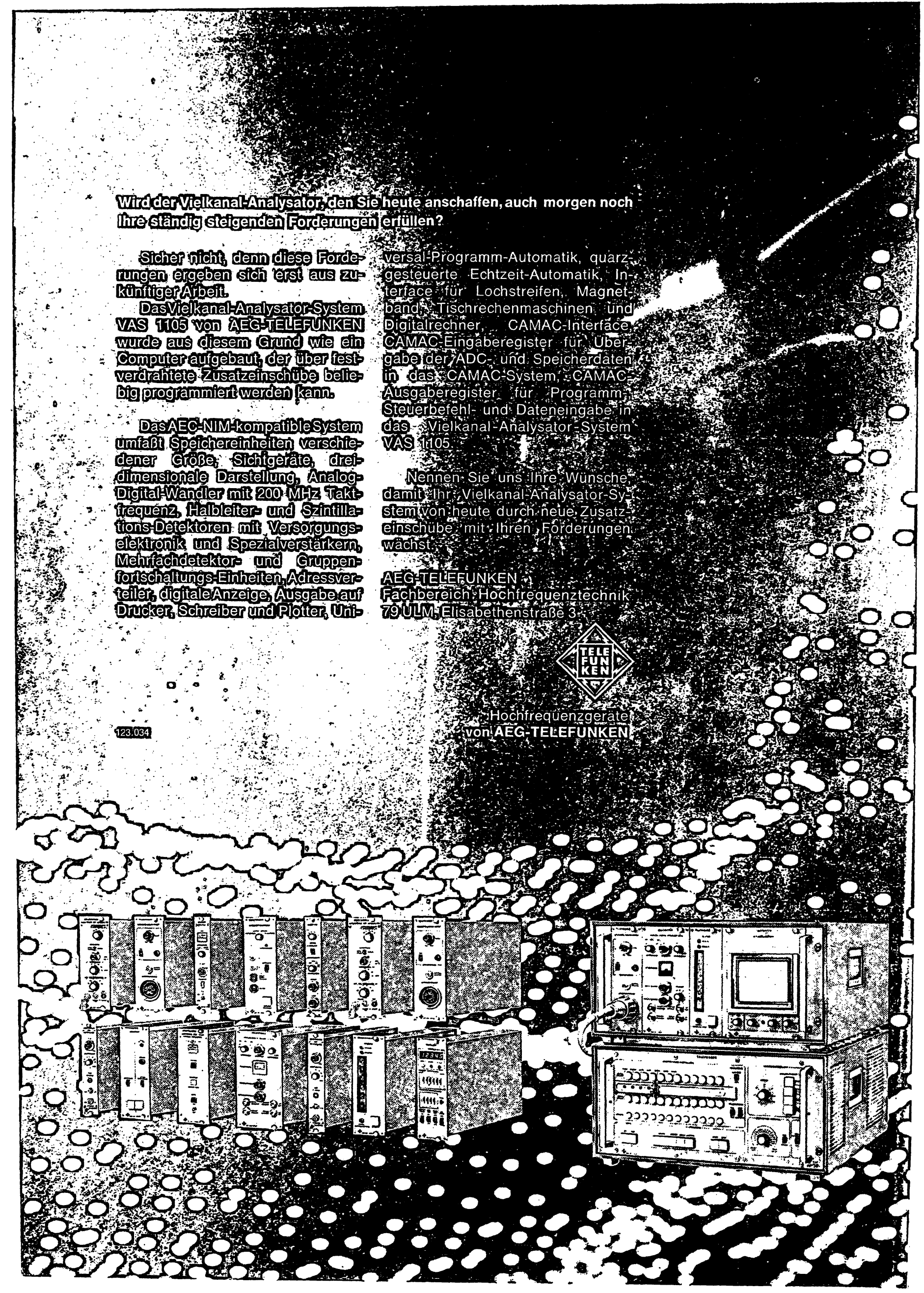


1. Dic Chylomikronen ( $\mathrm{d}=0,9-0,95 \mathrm{~g} / \mathrm{ml}$ ).

2. Die Very-Low-Density-Lipoproteins; VLDL $\quad(d=0,95-$ $1,006 \mathrm{~g} / \mathrm{ml}$ ).

3. Die Low-Density-Lipoproteins; $\operatorname{LDL}(\mathrm{d}=1,006-1,063 \mathrm{~g} / \mathrm{ml})$.

4. Die High-Density-Lipoproteins; HDL $(d=1,063-1,21 \mathrm{~g} / \mathrm{ml}$ ).

Bedingt durch qualitative wie quantitative Unterschiede in ihrem Proteinanteil lassen sich die vier Dichtefraktionen der Plasmalipoproteine bei elektrophoretischer Trennung in vier entsprechende Banden auftrennen:

1. Die nicht wandernden Chylomikronen.

2. Die mit den $\beta$-Globulinen wandernden $\beta$-Lipoproteine, die den LDL entsprechen.

3. Die mit den $\alpha_{2}$-Globulinen wandernden prä- $\beta$-Lipoproteine, die den VLDL entsprechen und

4. die mit den $\alpha_{1}$-Globulinen wandernden $\alpha$-Lipoproteine, die den HDL entsprechen.

Sowohl die Dichteklassen der Plasmalipoproteine wie ibre elektrophoretisch trennbaren Fraktionen stellen nun aber heterogene Gruppen hinsichtlich ihrer Proteinanteile, der sogenannten Apolipoproteine, dar. Durch eine Viclzahl weitreichender physikochemischer, chemischer und immunologischer Untersuchungen konnten im Plasmalipoproteinspektrum des Menschen wenigstens 3 voneinander verschiedene Apolipoproteine demonstriert werden. Wir bezeichnen diese Apolipoproteine, die sich in ihrer Aminosäurezusammensetzung, wie in ihren terminalen Aminosäuren, ihrem Molekulargewicht wie ihrer antigenen Determinante voneinander unterscheiden, als Apo A, Apo B und Apo C. Hicraus ergibt sich die dritte und vom physiologisch-chemischen Standpunkt aus gesehen wertvollste Klassifizierung der Plasmalipoproteine, eine Einordnung in Familien mit gleichen Apolipoproteinen.

$\mathrm{Zu}$ unterscheiden sind:

1. LP-A (Lipoprotein A) mit Apo A als Apolipoprotein.

2. LP-B (Lipoprotein B) mit Apo B als Apolipoprotein.

3. LP-C (Lipoprotein C) mit Apo $C$ als Apolipoprotein.

Den Apolipoproteinen kommt nämlich die zentrale Rolle bezüglich der Struktur, der Protein-Lipid-Zusammensetzung und somit dem Stoffwechsel der Lipoproteine zu. Es ist wahrscheinlich, $\mathrm{da} B$ die verschiedenen Apolipoproteine eine unterschiedliche Kapazität besitzen, Fettsäuren und Phospholipide kovalent zu binden. Solche Bindungen besitzen einen lipophilen . Charakter und sind von entscheidender Bedeutung bei der endgültigen Protein-Lipid-Zusammensetzung eines Lipoproteins. In ähnlicher Weise können die Protein-Kohlenhydratbindungen am Apolipoprotein und ihre Kohlenhydratanteile selbst eine Rolle spielen.

Es erscheint daher einleuchtend und es gibt bereits eine Reihe biochemischer Hinweise dafür, daß kleinste Änderungen am Proteinanteil der Plasmalipoproteine zu neu strukturierten Lipoproteinen führen können oder müssen.

Es war das Ziel der vorliegenden Arbeit, durch die Analyse der Plasmalipoproteinfraktionen Einblicke in den Plasmalipidtransport bei der Hyperthyreose, einer sekundären Hypolipoproteinämie zu erhalten.

\section{Material und Methoden}

Insgesamt wurde das Plasma von 33 Patienten beiderlei Geschlechts mit biochemisch wie klinisch gesicherter Hyperthyreose untersucht. Bei 3 der untersuchten Patienten lag ein toxisches Adenom vor. Die erste Blutentnahme zur Analyse der Plasmalipoproteine (in vereinzelten Fällen wurde eine Plasmapherese durchgeführt) wurde vor Therapiebeginn und in der Regel $10 \mathrm{Stdn}$. nach der letzten Mahlzeit vorgenommen. In 2 Fällen wurden Verlaufskontrollen während der therapeutischen Einstellung und in etwa der Hälfte der Fälle Nachuntersuchungen nach optimaler Therapie durchgeführt.

Isolicrung und Auftrennung der Plasmalipoprotcinfraktionen (vgl. Schema 1)

Das Plasma oder Serum der Patienten wurde durch entsprechende Zugabe von $\mathrm{NaBr}$ auf eine Lösungsdichte von $\mathrm{d}=1,063 \mathrm{~g} / \mathrm{ml}$ gebracht und in der Ultrazentrifuge (Spinco-Modell L/2) zentrifugiert. Alle Ultrazentrifugenläufe wurden bei $105000 \mathrm{~g}$ während $22 \mathrm{Stdn}$. bei $4^{\circ} \mathrm{C}$ in cinem Typ 50-TI Rotor durchgeführt. Der durch eine Schneidetechnik gewonnene Úberstand mit der Dichte von $\mathrm{d}<1,063 \mathrm{~g} / \mathrm{ml}$ wurde durch Dialyse gegen eine $\mathrm{NaCl}$-Lösung $(\mathrm{d}=1,006 \mathrm{~g} / \mathrm{ml})$ auf cine Dichte von $\mathrm{d}=1,006 \mathrm{~g} / \mathrm{ml}$ gebracht und abermals unter den angegebenen Bedingungen ultrazentrifugiert, um die Fraktionierung der VLDL und LDL zu erreichen. Der Unterstand $(\mathrm{d}=1,063 \mathrm{~g} / \mathrm{ml})$ wurde zur Isolierung der HDL-Fraktion durch entsprechende $Z$ ugabe von $\mathrm{KBr}$ auf eine Dichte von $\mathrm{d}=1,21 \mathrm{~g} / \mathrm{ml}$ gebracht und erneut ultrazentrifugiert. Um eine Trennung der $\alpha$-Lipoproteine der HDL-Fraktion von dem hier erstmalig beschriebenen abnormen $\beta$-HDL (siehe Resultat) $\mathrm{zu}$ erreichen, wurde der $\mathrm{d}=1,063 \mathrm{~g} / \mathrm{ml}$ Unterstand ciner Heparinpräzipitation (siehe unten) unterworfen und die $\alpha$-Lipoproteine aus dem Filtrat durch Ultrazentrifugation bei der Dichte $\mathrm{d}=1,21 \mathrm{~g} / \mathrm{ml}$ im Übcrstand gewonnen. Das gelöste Heparinpräzipitat wurde zur endgültigen Reinigung und genauen Analyse der Dichte des $\beta$-HDL zwei weiteren Ultrazentrifugationen unterworfen. Nach dem ersten Lauf bei einer Dichte von $\mathrm{d}=1,063 \mathrm{~g} / \mathrm{ml}$ wurde der Unterstand auf eine Dichte von

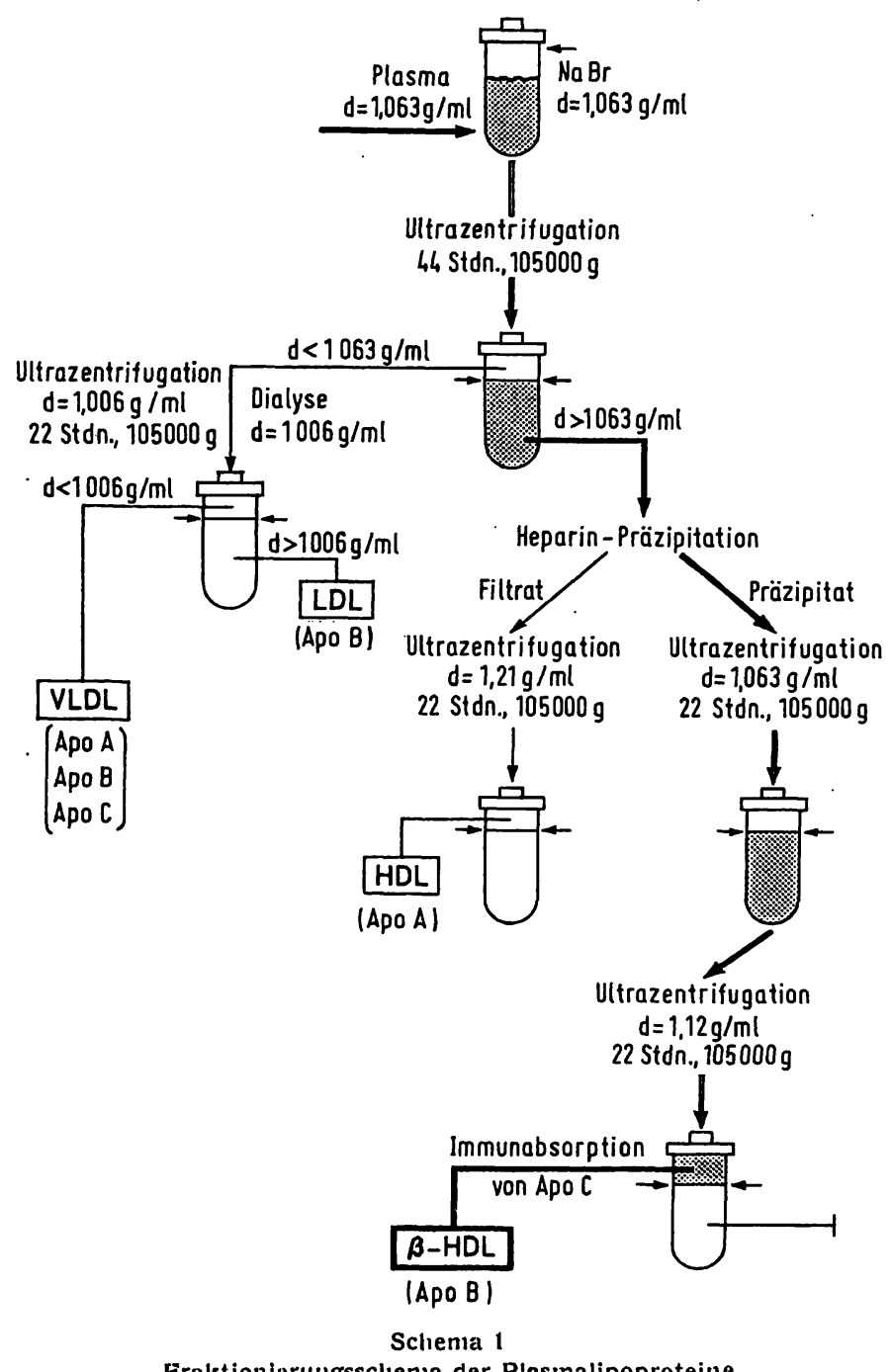

Fraktionierungssclienıa der Plasmalipoproteine 
$1,12 \mathrm{~g} / \mathrm{ml}$ eingestellt und erncut unter den angegebenen Bedingungen zentrifugiert. Der Uberstand der letzten Ultrazentrifugation cnthiclt nur das abnormc $\beta$-HDL, in einigen Fällen auch Ljpoprotein-C, das aber durch Immunabsorption mit anti-Apo $C$ Serum quantitativ eliminiert werden konnte.

Alle isolierten Plasmalipoproteinfraktionen wurden vor der weiteren Analyse ausgiebig (48 Stdn.) unter ständigem Wechsel bei $4^{\circ} \mathrm{C}$ gegen 0,9 proz. $\mathrm{NaCl}-\mathrm{Lösung}$ dialysiert.

\section{Quantitative Bestimmung des abnormen $\beta$-HDL}

Zur quantitativen Bestimmung des $\beta$-HDL wurden $5 \mathrm{ml} \mathrm{Nüchtern-}$ plasma oder -Serum der Patienten bei einer Dichte von $\mathrm{d}=$ $1,063 \mathrm{~g} / \mathrm{ml} 48 \mathrm{Stdn}$. lang bei $4^{\circ} \mathrm{C}$ und $105000 \mathrm{~g}$ zentrifugiert, am Unterstand nach einer 12 -stdg. Dialyse gegen 0,9 proz. $\mathrm{NaCl}$ Lösung eine Heparinpräzipitation vorgenommen und am gelösten Präzipitat das Cholesterin bestimmt. Als Umrechnungsfaktor vom Cholesteringehalt des Heparinpräzipitats auf Gesamtplasmakonzentration $\beta$-HDL (in $\mathrm{mg} / \mathrm{l}$ ) wurde der Faktor 800 eingesetzt. Er errechnet sich aus dem prozentualen Gehalt an Cholesterin des $\beta$-HDL und dem Cholesteringehalt des Heparinpräzipitats der HDL-Fraktion.

Auftrennung der Proteinanteile des abnormen $\beta$-HDL Das Apo $\beta$-HDL setzt sich aus zivei Proteinanteilen zusammen. Dem normalen Apo B und einem zweiten, als $\mathrm{H}_{1}$ bezeichneten Protein. Die Trennung der beiden Proteine gelang nach totaler Delipidierung des $\beta$-HDL durch Äthanol-Äther. Hiernach bleibt $\operatorname{der}$ Apo B Anteil des $\beta$-HDL unlöslich, während das $\mathrm{H}_{1}$-Protein leicht wasserlöslich ist.

\section{Lipoproteinelektrophorese}

Die Lipoproteinelektrophorese des Gesamtplasmas wie der isolierten Plasmalipoproteinfraktionen wurde auf Papier nach LEES und HATCH (16) und in Agarose/Agar nach der von GRETEN und SEIDEL (17) angegebenen Methode unter Zusatz von Albumin und unter Verwendung eines Veronalpuffers ( $\mathrm{pH} 8,6$; Ionenstärke 0,05$)$ durchgeführt. Als Lipidfarbstoff diente Öl-Rot-O.

\section{Präzipitation mit Polyanionen}

Die von Burstern und Samatlle (18) beschriebene HeparinPräzipitation zur Isolierung von $\beta$-Lipoproteinen wurde leicht abgewandelt. Auf $100 \mathrm{ml}$ des Unterstandes $(\mathrm{d}=1,063 \mathrm{~g} / \mathrm{ml})$ wurden nach Dialyse gegen 0,9proz. NaCl-Lösung $4 \mathrm{ml}$ einer 5 proz. Heparinlösung und $5 \mathrm{ml}$ einer $1 \mathrm{M}$ Manganchloridlösung zugesetzt. Nach 30 Min. Stehen bei +25 bis $+30^{\circ}$ wurden die präzipitierten Lipoproteine durch Zentrifugation während 20 Min. bei 15000 U./Min. getrennt und der Úberstand zur Isolierung der $\alpha$-HDL weiter verwandt (siehe oben). Das Ptäzipitat wurde in einem Gemisch aus $1 \mathrm{ml}$ einer 10proz. Na-Citrat- und $2 \mathrm{ml}$ einer 20proz. NaCl-Lösung gelöst und mit einem $1 \mathrm{~mm}$ Tris-Puffer $\mathrm{pH} 7,6$ auf $100 \mathrm{ml}$ verdünnt und anschließend unter Zugabe von $5 \mathrm{ml}$ einer $1 \mathrm{M}$ Mangonchloridlösung repräzipitiert. Dieser Prozeß wurde zweimal wiederholt und das letzte Präzipitat wie oben beschrieben gelöst, anschließend während $30 \mathrm{Stdn}$. gegen 9proz. $\mathrm{NaCl}$ - und $12 \mathrm{Stdn}$. gegen eine 5proz. Barium-Chloridlösung bei $4^{\circ} \mathrm{C}$ dialysiert. Der Heparin-Barium-Chloridkomplex konnte danach durch Zentrifugation mit 5000 U/.Min. aus der gelösten $\beta$-HDL-Fraktion eliminiert werden, die im Anschluß daran $48 \mathrm{Stdn}$. lang bei $4^{\circ} \mathrm{C}$ gegen eine 0,9 proz. $\mathrm{NaCl}$-Lösung dialysiert wurde, um sie später im physiologischen Milieu zu analysieren.

\section{Immunelektrophorese und Immundiffusion}

Proben von Gesamtplasma, isolierte intakte Plasmalipoproteinfraktionen, wie delipidierte Plasmalipoproteinfraktion wurden mit der Doppelimmundiffusionstechnik in 1proz. Agar nach OUCHTERLONY (19) und der Immunelektrophoresetechnik in 1proz. Agarose (20) unter Verwendung eines Veronalpuffers ( $\mathrm{pH} 8,6$; Ionenstärke 0,005) analysiert. Alle Platten wurden 24 bis $36 \mathrm{Stdn}$. in einer feuchten Kammer zur vollen Entwicklung der Präzipitationslinien bei $37^{\circ} \mathrm{C}$ inkubiert und nach mehrmaligem Waschen (1 mM Tris-Puffer $\mathrm{pH} 7,6$ ) und Trocknen mit AmidoSchwarz auf Protein und Öl-Rot-O auf Lipid angefärbt. Als
Antiseren wurden Seren gegen menschliches Albumin, $\alpha_{2}$-Makroglobulin, Haptoglobin, IgA, IgG, IgM, IgE, Transferrin, Caeruloplasmin, $\beta_{1}$-C-Makroglobulin, $\beta_{2}$-Glykoprotein, Fibrinogen, Creaktives Protein, $\alpha_{2}$-HS-Glykoprotein wie Seren gegen HumanVollserum der Firma Behring-Werke Marburg/Lahn und der Firma Meath, Paines and Byrne LTD, Greenford, England verwandt. Die Antiseren zum Nachweis der $\alpha$-Lipoproteine, $\beta$ Lipoproteine, des Lipoprotein $C$, des $L_{\mathrm{P}}(\mathrm{a})$-Lipoproteins sowie die Antiseren gegen das abnorme $\beta$-HDL wurden nach einer früher angegebenen Methode (21-23) im eigenen Laboratorium durch Immunisierung von Kaninchen hergestellt. Die verwendeten Antiseren wurden vor dem Gebrauch auf ihre Spezifität und Titer getestet.

\section{Immunabsorption}

Zur Immunabsorption wurde zunächst das optimale Konzentrationsverhältnis des Antiserums zur antigenen Lösung mittels einer Mikrotitrationsmethode festgelegt. Das entsprechend angesetżte Antigen-Antikörper-Gemissch wurde während $3 \mathrm{Stdn}$. bei$37^{\circ} \mathrm{C}$ inkubiert und anschließend $12 \mathrm{Stdn}$. bei $4^{\circ} \mathrm{C}$ gehalten. Danach wurde das Immunpräzipitat durch Zentrifugation bẹi $10000 \mathrm{U}$./ Min. von der verbleibenden Lösung getrennt.

Protein-und Lipidbestimmung

Die isolierten Lipoproteinfraktionen wurden in ihrem Proteingehalt nach LowRY und Mitarbeitern (24), in ihrem Cholesteringehalt nach SPERRY und WeBB (25), in ihrem Phospholipidgehalt nach GerLACH und Deutrcke (26) und in ihrem Triglyceridgehalt nach vaN HANDEL und ZILVERSMIT (27) bestimmt. Um von Lipid-Phosphor auf Phospholipid umzurechnen, wurde ein Faktor von 25 eingesetzt. Besonders lipidreiche Fraktionen wurden vor der Proteinbestimmung mit Äther extrahiert.

\section{Polyacrylamid-Elektrophorese}

Die Polyacrylamid-Elektrophorese wurde im Cañălco-Modell mit 6 Einheiten nach den Angaben von Davrs (28) und unter Verwendung eines kontinuierlichen Tris-Glycin-Puffers $\mathrm{pH} \mathrm{8,8}$ durchgeführt. Das Acrylamidtrenngel bestand aus einer oberen, 3,5proz. und einer unteren, 7,5proz. Schicht, die fugenlos aneinander anschlossen. Die Lipoproteinfraktionen wurden entweder vor der elektrophoretischen Trennung mit Sudan Schwarz auf Lipid vorgefärbt oder nach elektrophoretischer Trennung mit Amido Schwarz auf Protein gefärbt.

\section{Elektronenmikroskopie}

Die elektronenmikroskopischen Aufnahmen der isolierten $\beta$ HDL-Fraktionen wurden nach Negativfärbung durch 1proz. Kalium-Phosphorwolframsäure mit einem Siemens Elmiskop Typ 101 unter Verwendung von kohlebeschichteten CollodiumKupfernetzen vorgenommen. In einzelnen Fällen wựden die Präparationen vor der Färbung mit 3proz. Glutaraldehyd in destilliertem Wasser fixiert.

\section{Aminosäureanalyse}

Zur Aminosäureanalyse wurden die total delipidierten Lipoproteinfraktionen nach genauer Einwaage $18 \mathrm{Stdn}$. lang bei $110^{\circ} \mathrm{C}$ in $6 \mathrm{~N} \mathrm{HCl-Lösung} \mathrm{unter} \mathrm{Verschluß} \mathrm{hydrolysiert,} \mathrm{anschließend} \mathrm{im}$ Vakuum bei $40-50^{\circ} \mathrm{C}$ eingedampft und in einem Na-Citrat-Puffer pH 2,2 gelöst. Die Aminosäureanalyse erfolgte in einem Beckman-Unichrom AAA. Die neutralen und sauren Aminosäuren wurden auf einer Kationenaustauschsäule von $50 \mathrm{~cm}$ Länge mit einem Natrium-Citrat-Puffer ( $\mathrm{pH} 3,28$ und $\mathrm{pH} 4,2$ ), die basischen Aminosäuren auf einer Kationenaustauschsäule von $16 \mathrm{~cm}$ Länge in einem Citrat-Puffer ( $\mathrm{pH} 5,28$ ) eluiert. Tryptophan und Cystein wurden nicht bestimmt. Die Bestimmung der N-terminalen Aminosäure des Apo- $\beta$-HDL wurde nach der Dansylchloridmethode (29) durchgeführt.

Partielle und totale Delipidierung der Lipoproteinfraktionen

Die partielle Delipidation wurde mit alkalisiertem Diäthyläther vorgenommen. Hierzu wurden die Lipoproteinlösungen im 
Volumenverhältnis 1:50 mit Diäthyläther im verschlossenen Rundkolben über $20 \mathrm{Stdn}$. bei $4^{\circ} \mathrm{C}$ kräftig geschüttelt und anschließend die in der wäßr. Phase befindlichen Lipoproteine mit einem Scheidetrichter getrennt. Dié letzten Spuren von $X_{\text {ther }}$ wurden durch Einblasen von Stickstoff in die Lipoproteinlösung eliminiert.

Die totale Delipidierung der Lipoptoteinfraktion erfolgte nach ciner Modifikation der Methode von Scanu und Mitarbeitern (30). Jede Fraktion wurde hierzu lyophilisiert und anschließend dreimal ausgiebig insgesamt $24 \mathrm{Stdn}$. bei $-20^{\circ} \mathrm{C}$ in einem $X_{\text {thanol- }}$ Axther-Gemisch 3:2( $\mathrm{v} / \mathrm{v})$ extrahiert. Nach der letzten Behandlung mit dem Lösungsmittel wurden die Proteinanteile bei 5000 U./ Min. abzentrifugicrt und unter Stickstoff getrocknet, um die letzten Spuren des Lösungsmittels zu entfernen.

Lipidbeladung von isolierten Lipoprotcinfraktionen Die Lipidanreicherung wurde in vitro an isolicrten, intakten $\beta$-HDL-Fraktionen, partiell delipidierten normalen $\beta$-Lipoproteinen wie total delipidicten $\alpha$-Lipoproteinen nach der Methode von SCanu (31) vorgenommen. Als Lipide wurden den Fraktionen mit Ultraschall behandelte Lipidextrakte von normalem LDL, intakte isolierte LDL oder Vollplasma von Patienten mit ciner Hyperlipoproteinämic vom Typ II oder vom Typ IV angcboten. Die Inkubation erfolgte bei $37^{\circ} \mathrm{C}$ während $12 \mathrm{Stdn}$. Als Kriterium einer erfolgreichen Lipidbeladung galt bei den partiell delipidierten $\beta$-Lipoproteinen wie bei den total delipidierten $\alpha$ Lipoproteinen die Anfärbbarkcit ihrer Immunpräzipitationslinien mit Öl-Rot-O nach der Inkubation, bei $\operatorname{dem} \beta$-HDL dic Flotation in der Ultrazentrifuge bei ciner Lösungsdichte von $d=1,063 \mathrm{~g} / \mathrm{ml}$.

\section{Ergebnisse}

Qualitative Zusammensetzung der Dichtefraktionen der Plasmalipoproteine bei der Hyperthyreose

Normalerweise finden sich in der High-Density-Lipoproteinfraktion $(\mathrm{d}=1,063-1,21 \mathrm{~g} / \mathrm{ml}$ ) nur Lipoproteine mit $\alpha$-Mobilität bei elektrophoretischer Trennung (32-35), während die Lipoproteine der Dichteklasse $\mathrm{d}<1,063 \mathrm{~g} / \mathrm{ml}$ als $\beta$ - bzw. prä- $\beta$-Lipoproteine wandern. Dies gilt streng für die Plasmalipoproteinfraktionen von gesunden Kontrollpersonen wie von Patienten mit Dyslipoproteinämien. Eine einzige Ausnahme von dieser Regel stellte bisher das von BERG 1969 zuerst beschriebene $\mathrm{Lp}$ (a)-Lipoprotein dar (36), das trotz seiner Zugehörigkeit zur HDL-Fraktion prä- $\beta$-Mobilität entwickelt und offensichtlich keine Beziehung zu einer bestimmten Krankheit aufweist.

Nach der Fraktionierung des Plasmas von Patienten mit gesicherter Hyperthyreose bei der Dichte $\mathrm{d}=$ $1,063 \mathrm{~g} / \mathrm{ml}$ zeigt der Unterstand $(\mathrm{d}>1,063$ ) bei elektrophoretischer Trennung (vgl. Abb. 2) aber im Gegensatz zu Normalplasma nicht nur eine Bande im $\alpha$ Bereich, sondern darüber hinaus eine solche im Bereich $\operatorname{der} \beta$-Globuline. Wir bezeichnen diese abnorme und in dieser Arbeit erstmals beschriebene Lipoproteinbande der HDL-Fraktion als $\beta$-HDL. Die Konzentration des abnormen $\beta$-HDL kann die der normalen $\beta$-Lipoproteine erreichen oder gar übersteigen. Die Immunelektrophorese der HDL-Fraktion von Patienten mit Hyperthyreose zeigt entsprechend nicht nur die spezifische Reaktion gegen anti- $\alpha$-Lipoprotein-Serum im $\alpha_{1}$-Globulin Bereich, sondern darüber hinaus eine Präzipitationslinie gegen anti- $\beta$-Lipoprotein-Serum in der Position der $\beta$-Globuline (vgl. Abb. 3). Beide

Präzipitationslinien lassen sich mit Öl-Rot-O anfärben, was klar ihren Lipoproteincharakter anzeigt.

Um eine Ähnlichkeit zwischen $\operatorname{dem} \beta$-HDL und dem LP(a)-Lipoprotein BerG's auszuschlicßen, wurden die Plasmalipoproteinfraktionen eines Patienten mit Hyperthyreose, der $\mathrm{LP}(\mathrm{a})$ positjv war, untersucht. Das Heparinpräzipitat dessen HDL-Fraktion zeigt in der Lipidclektrophorese (vgl. Abb. 4) eine prä- $\beta$ - und $\beta$ Lipoproteinbande, aber nur die prä- $\beta$-Fraktion reagiert immunologisch mit dem spezifischen anti-L $\mathrm{p}$ (a) Serum, während beide Fraktionen mit dem anti- $\beta$-LipoproteinSerum reagieren. In keinem Fall reagierte ein isoliertes

$$
\begin{aligned}
& \text { VLOL + LOL }<1,063<\quad \text { HDL } \\
& \text { (i) } \\
& \begin{array}{ccc}
\alpha- & \alpha- \\
\text { Lipoproten } & & \alpha
\end{array}
\end{aligned}
$$

pra- $\beta$ -

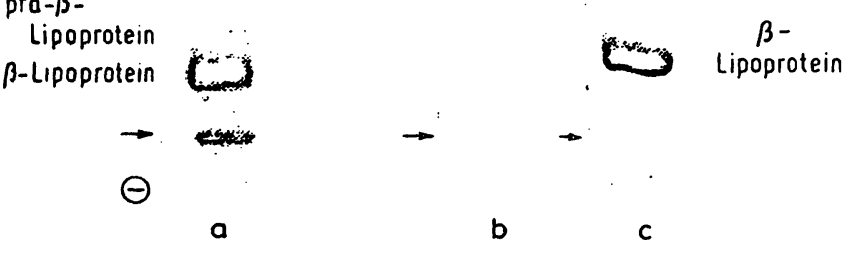

Abb. 2

Lipidelektropherogramme von isolierten Lipoproteinfraktionen in Iproz. Agarose. VLDL + LDL eines Patienten mit Hyperthyreose (a),
HDL von einer gesunden Normalperson (b) und einem Patienten mit Hypertliyreose (c)

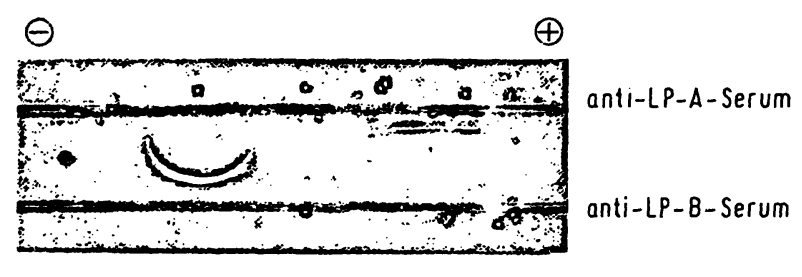

Abb. 3

Immunelektrophorese einer isolierten HDL-Fraktion eines Patienten mit Hyperthyreose in 1 proz. Agarose gegen anti-LP-A und anti-LP-B Serum

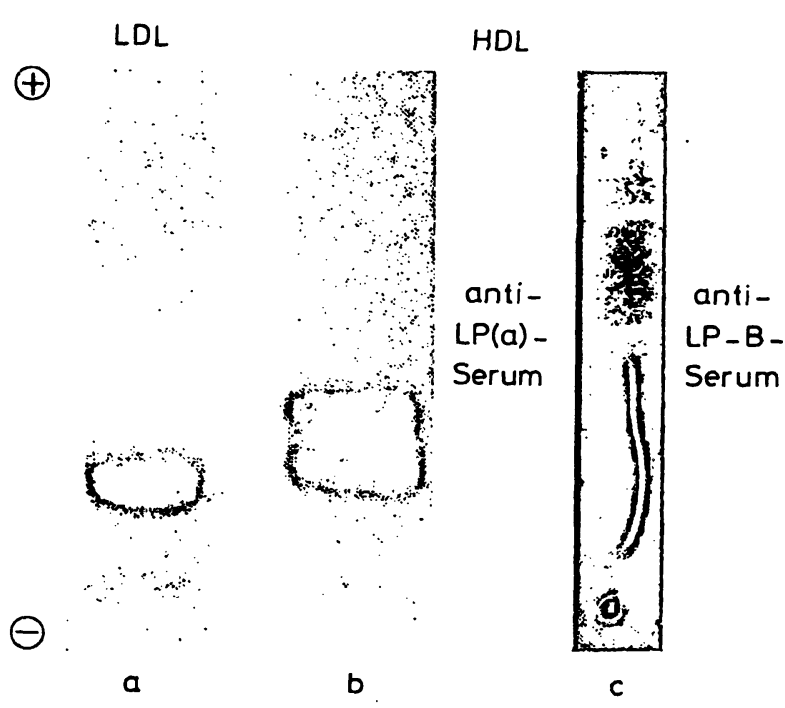

Abb. 4 Lipidelektrophorese einer LDL-Fraktion (a), sowie Lipid-(b) und
Immunelektrophorese (c) (1 proz. Agarose) des Heparinpräzipitats der HDL-Fraktion eines Patienten mit Hyperthyreose und nachgewiesenem Lp(a)-Lipoprotein. Als Antiseren wurden anti-Lp(a)-Serum und antiLP-B-Serum verwendet 
$\beta$-HDL immunologisch mit anti-Lp(a)-Serum. Dadurch ist eine Verwandtschaft oder Ähnlichkeit dieser beiden Lipoproteine ausgeschlossen.

Nachdem kürzlich gezeigt werden konnte, daß das Apo $C$ eine wesentliche Proteinkomponente des Lp(a)Lipoproteins darstellt (23), erklärt sich das gelegentliche Auftreten von Apo C im Heparinpräzipitat einer HDL-Fraktion von Patienten mit Hyperthyreose. Das Apo $C$ in einer solchen Präparation läßt sich durch Immunabsorption mit der Immunglobulinfraktion eines spezifischen anti-Apo C-Serums und nachfolgender Ultrazentrifugation bei der Dichte $\mathrm{d}=1,12 \mathrm{~g} / \mathrm{ml}$ eliminieren.

Die biochemische, elektrophoretische und immunologische Analyse der isolierten LDL- und VLDLFraktion von Patienten mit Hyperthyreose zeigt keine Abweichungen von der Norm. Wie entsprechend isolierte Fraktionen des Normalplasmas zeigen die VLDL von Patienten mit Hyperthyreose immunologisch Apo A, Apo B wie Apo C und wandern in der Lipidelektrophorese als prä- $\beta$-Lipoproteine. Ebenso zeigen die LDL, die allerdings bis zur Hälfte ihrer Normalkonzentration vermindert sein können, Apo B als Haupt-Apolipoprotein, nur in Spuren Apo A und wandern als $\beta$-Lipoproteine. Das Apo B der LDL zeigt eine normale Aminosäurezusammensetzung.

Isolierung des abnormen $\beta$-HDL (vgl. Tab. 2)

Die Isolierung des $\beta$-HDL aus der Plasmalipoproteinfraktion $\mathrm{d}=1,063 \mathrm{~g} / \mathrm{ml}$ gelingt unter Anwendung einer Heparinpräzipitation, einer Methode, die geeignet ist, auch die normalen $\beta$ - und prä- $\beta$-Lipoproteine von den $\alpha$-Lipoproteinen zu trennen. Da diese beiden Fraktionen jedoch ausschließlich in der Dichteklasse $\mathrm{d}<1,063 \mathrm{~g} / \mathrm{ml}$ vorkommen, finden sich in dem Heparinpräzipitat einer HDL-Fraktion ( $>1,063 \mathrm{~g} / \mathrm{ml}$ ) von Patienten mit Hyperthyreose nur das abnorme $\beta$-HDL, während die $\alpha$-Lipoproteine gelöst im Filtrat bleiben (vgl. Abb. 5). Die nachfolgende Analyse des gelösten Heparinpräzipitats in der Ultrazentrifuge bei
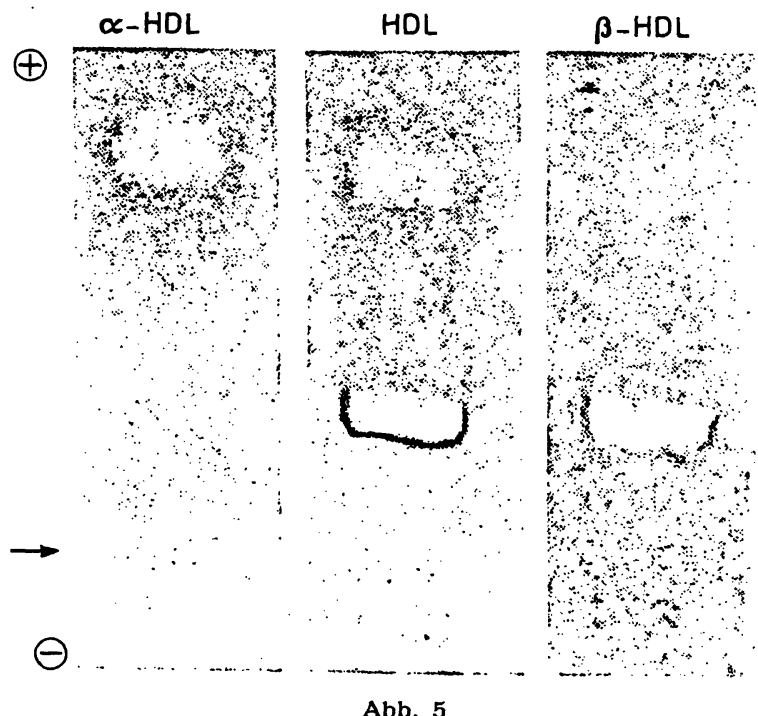

Lipidelektrophorese isolierter Lipoproteinfraktionen eines Patienten mit Hyperthyreose in 1 proz. Agarose der Dichte $\mathrm{d}=1,063 \mathrm{~g} / \mathrm{ml}$ und $1,21 \mathrm{~g} / \mathrm{ml}$ ergibt, daß es sich bei dem isolierten $\beta$-HDL um ein sogenanntes $\mathrm{HDL}_{2}$ ( $\left.\mathrm{d}=1,063-1,12 \mathrm{~g} / \mathrm{ml}\right)$ handelt. Weder der Uberstand $(\mathrm{d}=1,063 \mathrm{~g} / \mathrm{ml})$ noch der Unterstand $(\mathrm{d}=$ $1,12 \mathrm{~g} / \mathrm{ml}$ ) zeigen immunologisch eine Reaktion gegen anti- $\beta$-Lipoprotein-Serum.

\section{Charakterisierung des $\beta$-HDL}

Das isolierte $\beta$-HDL wandert in der Papierelektrophorese mit normaler $\beta$-Mobilität während ẹs in Agarose eine Mobilität zeigt, die im Vergleich zu den normalen $\beta$-Lipoproteinen leicht beschleunigt ist (vgl. Abb. 6). Diese Differenz ist wahrscheinlich eher auf Unterschiede in der Größe der Moleküle zurückzuführen als auf Unterschiede in ihrer Ladung. Im Elektronenmikroskop (vgl. Abb. 7) erscheinen isolierte $\beta$-HDL als runde Partikel mit einem Durchmesser von $15 \mathrm{~nm}$ und damit kleiner im Vergleich zu den normalen $\beta$-Lipoproteinen der LDL-Fraktion (37) mit einem Durchmesser bis $26 \mathrm{~nm}$. Entsprechend dringt das isolierte $\beta$-HDL bei einer Polyacrylamidelektrophorese in ein 7,5proz. Gel ein, im Gegensatz zu den normalen $\beta$ Lipoproteinen, die nur in Gelkonzentrationen von $3,5 \%$ und geringerer wandern (vgl. Abb. 8).

$\mathrm{Da}$ die High-Density-Lipoproteine einen größeren Protein- und geringeren Lipidanteil aufweisen als die Low-Density-Lipoproteine, war zu vermuten, daß sich
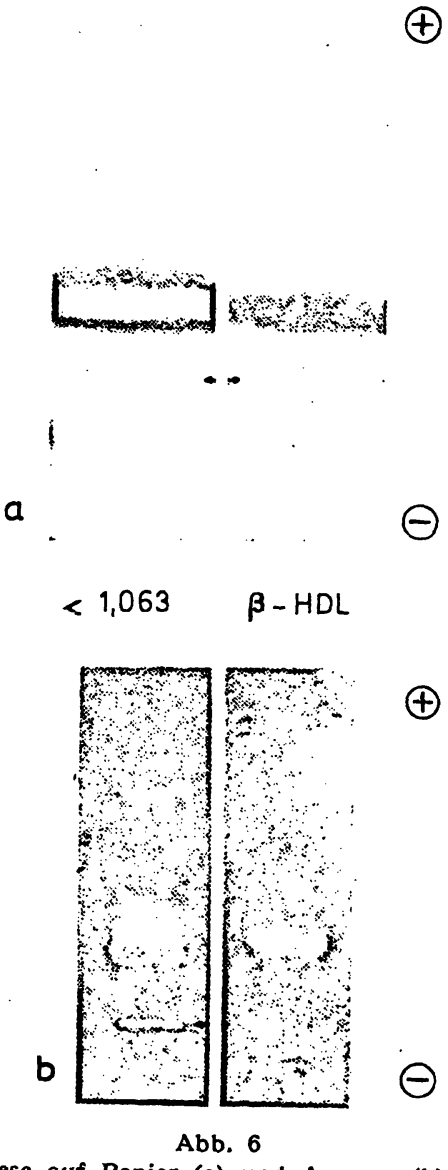

Lipidelektrophorese auf Papier (a) und Agarose (b) einer isolierten

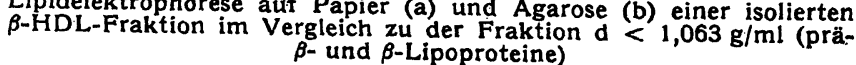




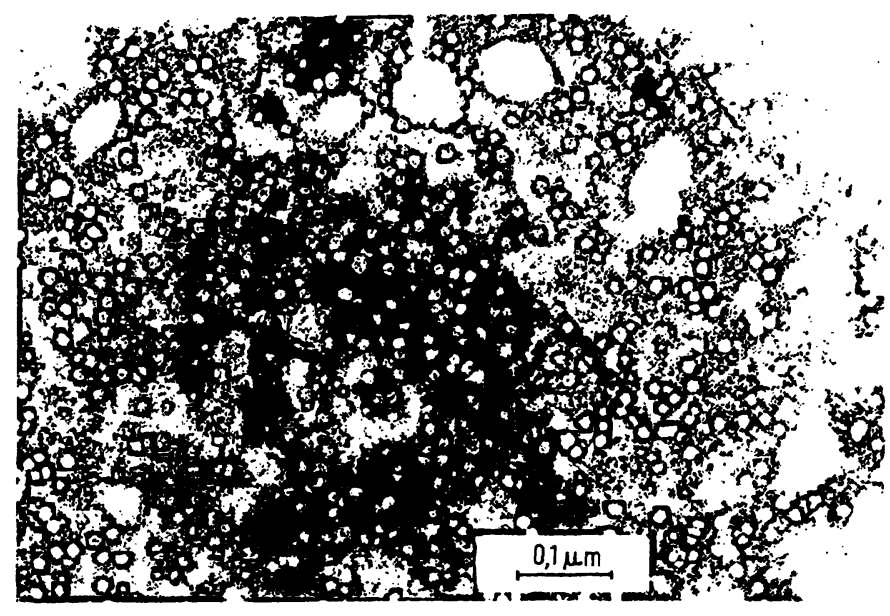

Abb. 7

Elektronenmikroskopische Aufnahme einer isolierten $\beta$-HDL Präparation nach "negative staining" mit 1 proz. Phosphorwolframsäure

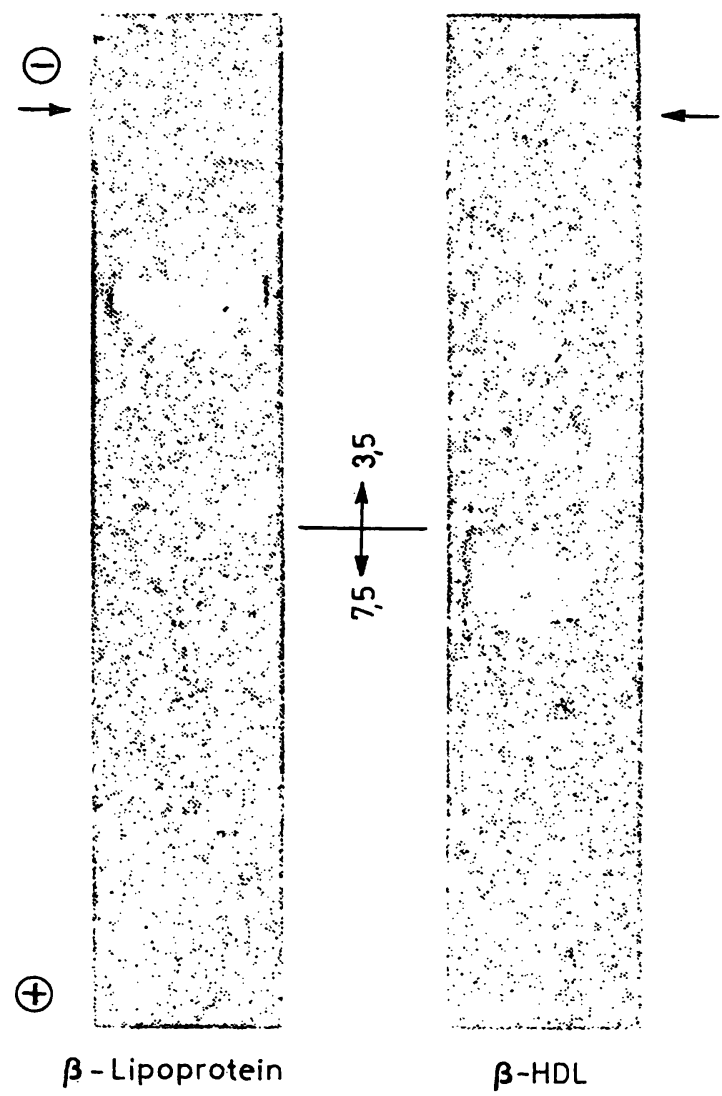

Abb. 8

Polyacrylamidelektrophorese normaler isolierter $\beta$-Lipoproteine und eines isolierten $\beta-\mathrm{HDL}$ in einem geschichteten 3,5 proz. $/ 7,5$ proz.

auch das $\beta$-HDL in seinem Protein/Lipid-Verhältnis und somit in seiner Protein-Lipid-Zusammensetzung von den normalen $\beta$-Lipoproteinen unterscheidet. Die separate Bestimmung des Protein-, Cholesterin-, Triglycerid- und Phospholipidanteils am isolierten $\beta$-HDL bestätigt diese Annahme. Die Ergebnisse sind in Tabelle 2 wiedergegeben und zeigen, daß sich das $\beta$-HDL durch einen hohen Gehalt an Protein, der zu einem Anwachsen des Protein/Lipid-Quotienten führt, wie durch einen niedrigen Gehalt an Cholesterin im Vergleich zu den normalen $\beta$-Lipoproteinen aus- zeichnet. Der Gehalt an Triglyceriden und Phospholipiden ist bei beiden Lipoproteinfraktionen ähnlich, wenn nicht identisch.

Tab. 2

Protein-Lipid-Zusammensetzung isolierter Lipoproteinfraktionen

\begin{tabular}{lccccc}
\hline & Protein & $\begin{array}{c}\text { Chole- } \\
\text { sterin } \\
{[\%]}\end{array}$ & $\begin{array}{c}\text { Phospho- } \\
\text { lipide } \\
{[\%]}\end{array}$ & $\begin{array}{c}\text { Trigly- } \\
\text { ceride } \\
{[\%]}\end{array}$ & $\begin{array}{c}\text { Protein/ } \\
\text { Lipid- } \\
\text { quotient }\end{array}$ \\
\hline $\begin{array}{l}\text { Normales } \\
\beta-L i p o p r o t e i n\end{array}$ & 22 & 45 & 23 & 10 & 0,28 \\
$\beta$-HDL & 43 & 25 & 22 & 10 & 0,75 \\
\hline
\end{tabular}

Charakterisierung des Proteinanteils des $\beta$ HDL

Während die HDL-Fraktion von Patienten mit Hyperthyreose immunologisch nicht nur mit anti- $\alpha$-Lipoprotein-Serum sondern ebenso mit anti- $\beta$-LipoproteinSerum reagiert (vgl. Abb. 3), zeigt die isolierte $\beta$ HDL-Fraktion immunologisch nur noch eine Reaktion mit anti- $\beta$-Lipoprotein-Serum. Es reagiert weder in der Doppelimmundiffusion (vgl. Abb. 9) noch in der Immunelektrophorese mit Antiseren gegen Human$\alpha$-Lipoproteine, Lipoprotein C, Albumin oder irgend ein anderes Plasmaprotein. Diese Untersuchungen wurden bei unterschiedlichen Konzentrationen des Antigens und Antikörpers durchgeführt. Bei der Immundiffusion gegen anti- $\beta$-Lipoprotein-Serum erhält man eine volle Identität (vgl. Abb. 10) zwischen Kontrollserum, den $\beta$-Lipoproteinen der LDL-Fraktion und $\operatorname{dem} \beta$-HDL von Patienten mit Hyperthyreose. Dieser Befund zeigt eindeutig, daß am Aufbau des $\beta$-HDL dem Proteinanteil der normalen $\beta$-Lipoproteine, dem Apo B, eine wesentliche Rolle zukommt.

Nach dem immunologischen Verhalten des isolierten $\beta$-HDL, dessen Homogenität und Reinheit nicht nur durch die immunologischen Methoden, sondern darüber hinaus durch den Nachweis nur einer einzigen Bande in der Polyacrylamidelektrophorese erwiesen ist, würde man von einem anti- $\beta$-HDL-Serum erwarten, $\mathrm{da} B$ es nur mit Apo B immunologisch reagiert.

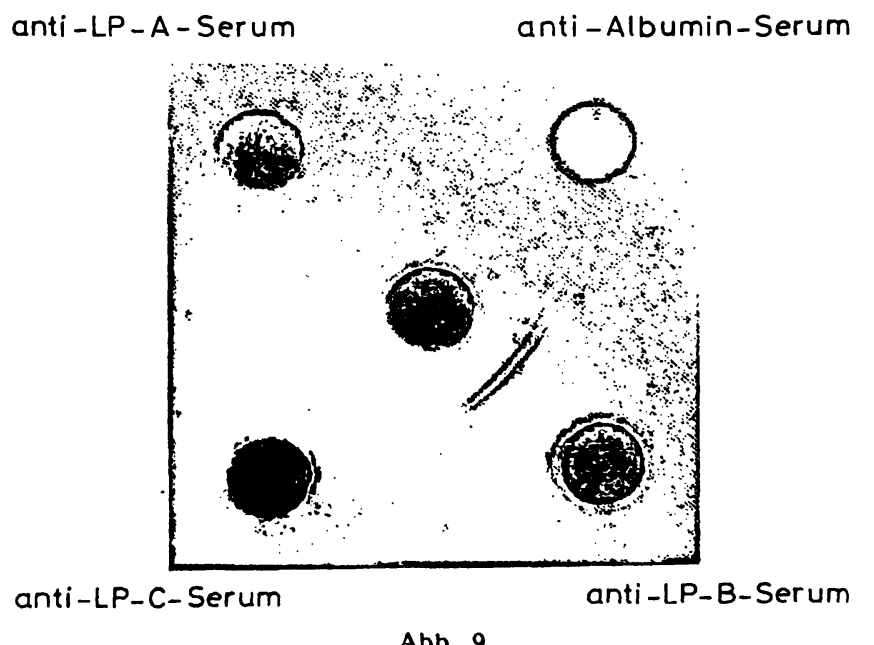
Immundiffusion eines isolierten $\beta-H D L$ gegen anti-LP-A-, anti-Al-
bumin-, anti-LP-B- und anti-LP-C-Serum 


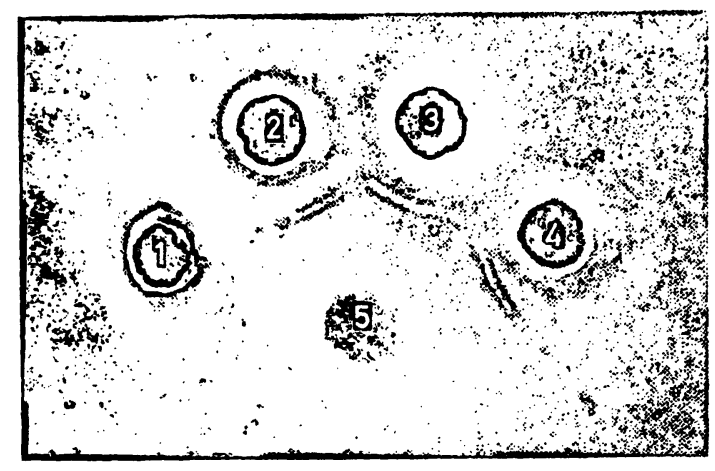

Abb. 10

Immundiffusion eines Kontrollserums (1), einer LDL-Fraktion (2), einer $\beta$-HDL-Fraktion (3) sowie des Vollplasmas eines Patienten mi Hyperthyreose (4) gegen anti-LP-B-Serum (5) in 1 proz. Agar

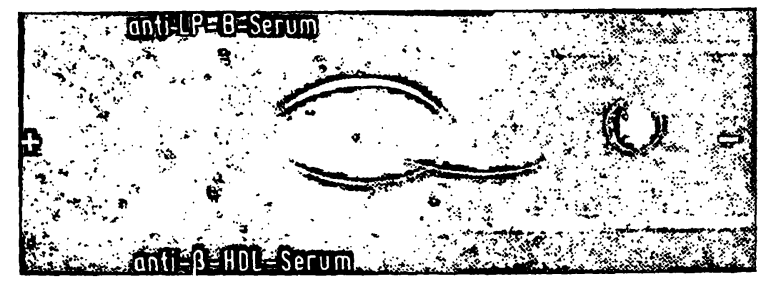

Abb. 11

Immunelektrophorese des Vollplasmas eines Patienten mit Hyperthyreose in 1proz. Agarose. Als Antiseren wurden anti-LP-B- und anti- $\beta$-HDL-Serum verwendet

Das vom Kaninchen nach i. p.-Injektion eines isolierten $\beta$-HDL gewonnene Antiserum gegen $\beta$-HDL reagiert aber in der Immunelektrophorese immer (verschiedene Präparationen bei verschiedenen Tieren) mit zwei Präzipitationslinien gegen Plasma von Patienten mit Hyperthyreose (vgl. Abb. 11), was darauf hinweist, $\mathrm{da} \beta$ der Proteinanteil des $\beta$-HDL wenigstens aus zwei Komponenten besteht. Eine Linie, die eine volle Idendität zu den normalen $\beta$-Lipoproteinen aufweist, entspricht dem Apo B und läßt sich mit Lipidfarbstoff anfärben. Die zweite, nicht identische Linie läßt sich nicht mit Lipidfarbstoff anfärben und entwickelt eine geringere elektrophoretische Mobilität in Agarose als die $\beta$-Lipoproteine. Sie zeigt sich in dem Bereich zwischen Start und $\operatorname{der} \beta$-Globulinposition.

Die zweite Proteinkomponente des $\beta$-HDL wird im folgenden als $\mathrm{H}_{1}$ bezeichnet. Das $\mathrm{H}_{1}$-Protein reagiert immunologisch nicht mit spezifischen Antikörpern gegen $\alpha_{2}$-Makroglobulin, Haptoglobin, IgG, IgM, $\operatorname{IgA}$, IgE, Caeruloplasmin, Transferrin, $\beta_{1}$ C-Makroglobulin, $\beta_{2}$-Glykoprotein, Fibrinogen, $C$-reaktives Protein, $\alpha_{2}$-HS-Glykoprotein, $\beta$-Lipoprotein, $\alpha$-Lipoprotein, Lipoprotein-C und Albumin, was eine Verwandtschaft mit diesen Plasmaproteinen ausschließt. Eine Ähnlichkeit des $\mathrm{H}_{1}$-Protein mit dem thyroxinbindenden Globulin (TBG) kann aufgrund seiner unterschiedlichen. elektrophoretischen Mobilität ausgeschlossen werden. Das TBG wandert bekanntlich als $\alpha_{-2}$-Globulin.

Immunologisch unterscheidet sich das $\mathrm{H}_{1}$-Protein ebenso eindeutig in seiner antigenen Determinante von allen bekannten Apolipoproteinen und zeigt darüberhinaus signifikante Unterschiede in seiner Aminosäurezusammensetzung $z u$ diesen. Auffällig ist sein relativ niedriger Gehalt an Histidin und relativ hoher Gehalt an Methionin im Vergleich zu bekannten Apolipoproteinen. Als N-terminale Aminosäure fanden wir für das $\mathrm{H}_{1}$-Protein Asparaginsäure.

Während verschiedene Antiseren gegen Human-Vollserum der Firma Behring-Werke Marburg/Lahn keine Kreuzreaktion mit dem $\mathrm{H}_{1}$-Protein zeigten, erhielten wir mit einer Charge von anti-Human-Serum der Firma Meath, Greenford, Englañd eine Immunpräzipitationslinie gegen das isolierte $\mathrm{H}_{1}$-Protein, die voll identisch mit jener des $\mathrm{H}_{1}$-Proteins gegen anti- $\mathrm{H}_{1}$ Serum war. Dies, wie die Tatsache, daß das anti- $\mathrm{H}_{1}$ Serum auch mit Normalplasma immunologisch reagiert, weist darauf hin, daß es sich bei dem $\mathrm{H}_{1}$-Protein um ein offenbar bisher nicht identifiziertes normales Plasmaprotein handelt, das bei der Hyperthyreose mit dem Apo B und Lipiden einen makromolekularen Komplex eingeht. Die strukturellen Beziehungen bzw. die Lokalisation der beiden Proteinanteile in diesem ProteinLipid-Komplex werden durch Abbildung 12 deutlich. $\mathrm{Da}$ ein monospezifisches anti- $\mathrm{H}_{1}$-Serum nicht mit intaktem $\beta$-HDL, aber sehr wohl mit dem delipidierten $\beta$-HDL reagiert und isoliertes $\beta$-HDL durch in vitro Inkubation nur ein anti- $\beta$-Lipoprotein-Serum, nicht aber ein anti- $\mathrm{H}_{1}-$ Serum erschöpft, scheint die $\mathrm{H}_{1}-\mathrm{Kom}$ ponente im Kern, der Apo B-Anteil an der Oberfläche des $\beta$-HDL lokalisiert zu sein.

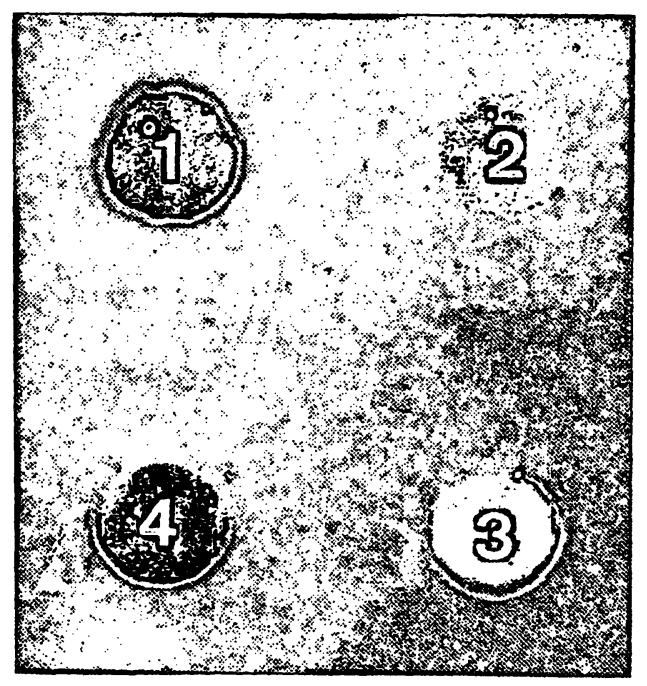

Abb. 12

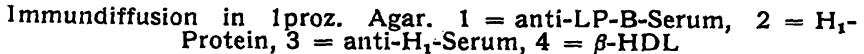

\section{Lipidbindungsvermögen des $\beta$-HDL}

$\mathrm{Da}$ der Cholesteringehalt des $\beta$-HDL gegenüber dem normalen $\beta$-Lipoprotein erniedrigt und sein Proteingehalt erhöht ist, sollte durch eine Serie von Lipidbindungsversuchen in vitro ein Einblick in die Lipidbindungskapazität des $\beta$-HDL gewonnen werden. Es wurde der Versuch unternommen, das isolierte $\beta$-HDL durch Inkubation mit Lipiden an Lipid anzureichern, um es damit aus seiner hohen, in eine für die $\beta$-Lipoproteine normale Dichtefraktion zu zwingen. Dies gelingt weder mit dem Lipidextrakt einer normalen 
LDL-Fraktion noch mit intaktem normalen LDL oder Vollplasma von Normalpersonen wie von Patienten mit einer Hyperlipoproteinämie vom Typ II oder Typ IV. Unter identischen Bedingungen ist es uns hingegen gelungen, partiell delipidierte normale $\beta$ Lipoptoteine oder total delipidierte Lipoproteine mit Lipid aufzuladen. Es läßt sich daraus schließen, $\mathrm{da}$ nicht das Angebot an Lipid, insbesondere an Cholesterin, sondern wahrscheinlich die spezifische Kombination eines normalen Apo $\mathrm{B}$ mit dem $\mathrm{H}_{1}$-Protein verantwortlich ist für die abnorme Protein-Lipid-Zusammensetzung des $\beta$-HDL und für das daraus resultierende abnorme physikochemische Verhalten dieses Lipoproteins.

Das Auftreten von $\beta$-HDL im Plasma von Patienten mit Hyperthyreose

In allen 33 untersuchten Fällen, in 3 Fällen handelt es sich um ein toxisches Adenom, bei denen die Diagnose einer Hyperthyreose durch die klinische Symptomatik wie klinisch-chemisch (T3-Test, T4/T3-Index, PBIBestimmung, Radiojodtest) klar gestellt werden konnte, ergab sich das Vorliegen des abnormen Plasmalipoproteins, des $\beta$-HDL. In keinem untersuchten Fall konnte das $\beta$-HDL noch nachgewiesen werden, nachdem es durch die. Therapie eindeutig zur Normalisierung der Stoffwechselfunktion gekommen war.

In Abbildung 13 sind der Verlauf des T4/T3-Index, die T3-Werte sowie die $\beta$-HDL-Konzentration bei einer 48-jährigen Patientin mit Hyperthyreose unter der Therapie dargestellt. Es zeigt sich eine gute Korrelation $\operatorname{der} \beta$-HDL-Konzentration mit den verglichenen Parametern, die sich parallel dem klinischen Bild änderten. Inwieweit die Konzentration des $\beta$-HDL den Schweregrad der Hyperthyreose widerspiegelt, kann allerdings erst nach der Bewertung einer größeren Anzahl von genau kontrollierten Fällen beurteilt werden.

Wie zu erwarten war und bekannt ist, ergaben hingegen die Bestimmungen des Gesamtcholesterins im Plasma der untersuchten Patienten keinen verläßlichen dia-

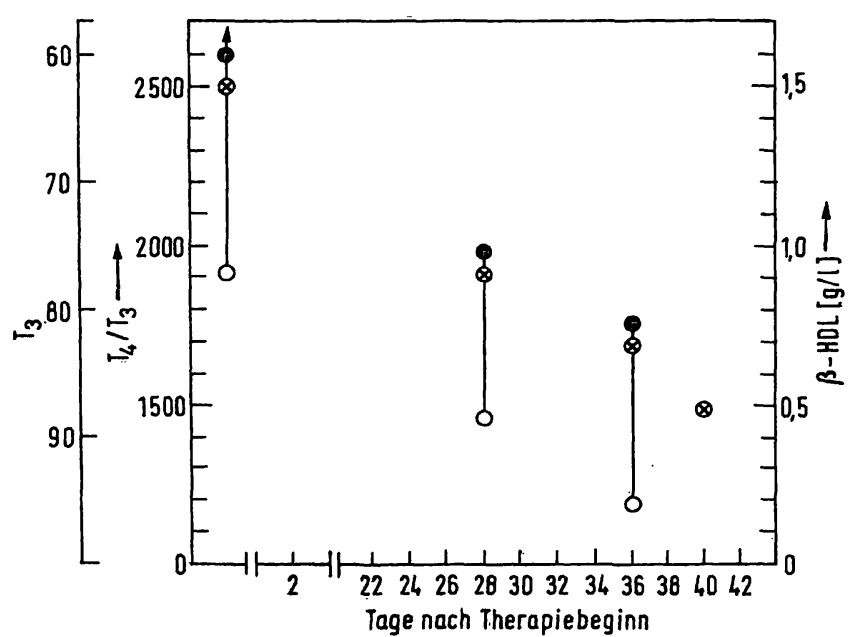

Abb. 13

Verlauf des $T_{2}$-Wertes $O$, des $T_{4} / T_{3}$-Index $\odot$ und der $\beta$-HDL-Konzentration $\otimes$ unter der Therapie einer Hyperthyreose gnostischen Hinweis für das Vorliegen oder den Ausschluß einer Hyperthyreose. Obgleich der Durchschnittswert unserer Patientengruppe mit $1,45 \mathrm{~g} / \mathrm{l}$ Plasmacholesterin unterhalb der Norm lag, - der niedrigste Wert vor der Therapie betrug $0,87 \mathrm{~g} / \mathrm{l},-$ können solche Werte wegen der großen individuellen Streuung nicht als sicherer diagnostischer Parameter herangezogen werden. Sie erlauben allenfalls einen gewissen Hinweis auf den Erfolg der Therapie $(5,8)$. Es zeigte sich hier wie bei allen Störungen des Fettstoffwechsels deutlich die beschränkte Aussagekraft einer isolierten Analyse der einzelnen Plasmalipidfraktionen und unterstreicht gleichzeitig die Bedeutung und den Wert der genauen Charakterisierung der Plasmalipoproteinfraktionen.

\section{Diskussion}

Patienten mit Hyperthyreose zeigen häufig niedrigere Plasmacholesterinwerte bei normalem Lipidelektropherogramm und normalen Plasmaphospbolipidwerten. Dieser scheinbare Widerspruch konnte durch den Nachweis, die Isolierung und biochemische Charakterisierung eines Lipoproteins von abnormen physikochemischen Eigenschaften im Plasma jener Patienten geklärt werden. Während die VLDL- und LDLFraktionen von Patienten mit klinisch gesicherter Hyperthyreose qualitativ keine Abweichungen von der Norm zeigen, finden sich in der HDL-Fraktion dieser Patienten nicht nur $\alpha$-Lipoproteine sondern darüber hinaus $\beta$-Lipoproteine in hoher Konzentration, die die $\operatorname{der} \beta$-Lipoproteine der LDL-Fraktion erreichen kann. Dieses abnorme $\beta$-Lipoprotein, das sich deutlich von dem Lp(a)-Lipoprotein BERG's unterscheidet und als $\beta$-HDL bezeichnet wird, kann durch eine Kombination von Ultrazentrifugation und Heparinpräzipitation isoliert werden. In seiner Protein-Lipid-Zusammensetzung unterscheidet sich das $\beta$-HDL von den normalen $\beta$ Lipoproteinen durch einen hohen Gehalt an Protein und einem niedrigen Gehalt an Cholesterin, während bezüglich der Triglyceride und Phospholipide kein Unterschied besteht.

$\mathrm{Da}$ die Dichte der Plasmalipoproteine allein eine Funktion ihrer Protein-Lipid-Zusammensetzung, insbesondere ihres Protein/Lipid Quotienten ist, ihre elektrophoretische Mobilität in Agarose aber durch die Ladung des an der Oberfläche lokalisierten Proteins festgelegt ist, und ihre Lipidanfärbbarkeit im wesentlichen auf dem Gehalt an Neutralfetten beruht, erklärt sich mit der Charakterisierung des $\beta$-HDL die bekannte Diskrepanz zwischen Plasma-Lipidwerten und Lipidelektropherogramm bei Patienten mit Hyperthyreose.

Die Erniedrigung der LDL-Fraktion (38-40) läuft parallel mit einem Absinken des Plasmacholesterins, das in dieser Fraktion am stärksten vertreten ist. Die damit normalerweise notwendig verbundene Abnahme der $\beta$-Lipoproteine und Plasmaphospholipide wird kompensiert durch das Auftreten eines abnormen $\beta$-Lipoproteins $(\beta-\mathrm{HDL})$, nicht von niedriger, sondern von hoher Dichte und mit einem, für ein $\beta$-Lipoprotein 
niedrigen Gehalt an Cholesterin, aber normalem Phospholipid- und Triglyceridgehalt.

Die Charakterisierung des Proteinanteils des $\beta$-HDL hat klar gezeigt, daß das $\beta$-HDL aus dem Apo B, dem Proteinanteil der normalen $\beta$-Lipoproteine und zusätzlich aus einem bisher nicht identifizierten Plasmaprotein (als $\mathrm{H}_{1}$ bezeichnet) besteht. $\mathrm{Da}$ sich die $\mathrm{H}_{1-}$ Proteinkomponente weder in der Immundiffusion noch durch Immunabsorption am intakten $\beta$-HDL nachweisen läßt, wohl aber nach Delipidierung, ist zu vermuten, $\mathrm{da} \beta$ das $\mathrm{H}_{1}$-Protein im Kern des $\beta$-HDL lokalisiert ist oder zumindest der größte Teil dieses Proteins durch Lipid bedeckt ist. Hierfür spricht auch die Tatsache, daß das $\beta$-HDL eine normale $\beta$-Mobilität entwickelt, die nur durch den normalen Apo B-Anteil gegeben sein kann, nicht aber durch den $\mathrm{H}_{1}$-Protein-Anteil. Befänden sich beide Proteine an der Oberfläche des $\beta$-HDL, wäre eine elektrophoretische Mobilität zu erwarten, die zwischen der des $\mathrm{H}_{1}$-Proteins und der des Apo B liegt.

Die Vorstellung solcher strukturellen Verhältnisse im Plasmalipoprotein ist nicht mehr unwahrscheinlich, nachdem bei Verschlußikterus ein Lipoprotein nachgewiesen werden konnte $(22,41)$, das aus einem Albuminkern besteht, der von Phospholipiden und einer zweiten Proteinkomponente, dem Apo C, umschlossen ist.

$\mathrm{Da}$ sich das isolierte $\beta$-HDL unter geeigneten Bedingungen nicht mit Lipiden anreichern läßt, der Apo BAnteil des $\beta$-HDL aber eine normale Aminosäurezusammensetzung zeigt, kann vermutet werden, daß die abnorme Protein-Lipid-Zusammensetzung des $\beta$-HDL nicht durch das Lipidangebot, sondern durch die spezifische Kombination des Apo B mit dem $\mathrm{H}_{1}$-Protein bestimmt wird. Diesem Befund kommt eine große theoretische Bedeutung $\mathrm{zu}$, da wir bis heute keine schlüssigen Vorstellungen haben über die Faktoren, die die Apolipoproteine zu Lipidbindungen befähigen bzw. sie in ihrer Lipidbindungskapazität determinieren.

Es wird weiteren Untersuchungen vorbehalten bleiben, die Rolle der Schilddrüse im Stoffwechsel des $\beta$-HDL abzuklären. Die vorliegenden Ergebnisse zeigen aber bereits deutlich, daß die Schilddrüse oder zumindest die Überfunktion dieses Organs nicht nur die Synthese und den Abbau der Plasmalipide beeinflußt, sondern darüber hinaus auch entscheidend ihren Transport im
Plasma. Sie bestätigen weiterhin, daß der bekannte Einfluß der Schilddrüsenhormone auf den Eiweißstoffwechsel (42-44) offensichtlich auch die Trägerproteine der Plasmalipoproteine betrifft. Bekannt ist seit 1958 (45) das Auftreten des Long Acting Thyreoid Stimulator (LATS), eines abnormen Immunglobulins (45-47) beim Morbus BASEDow. Obgleich das $\mathrm{H}_{1}$ Protein sicher kein Immunglobulin darstellt und sich das $\beta$-HDL im Unterschied zu dem LATS $(47,48)$ auch beim toxischen Adenom findet, erscheint es uns denkbar, daß ähnliche Mechanismen zum Auftreten des LATS und des $\mathrm{H}_{1}$-Proteins in seiner lipidbindungsaktiven Form, die in der Kombination mit einem normalen Apo B besteht, führen könnten. Im gleichen Zusammenhang erscheint ein kürzlich von CHOPRA und Mitarbeitern (49) aus der Schilddrüse extrahiertes Lipoprotein, das eine beträchtliche Hemmung des LATS bewirkt, von Interesse. Obgleich sich dieses Lipoprotein nur in der Schilddrüse, nicht aber im Plasma oder anderen Geweben fand, zeigte es in seinem Proteinanteil nicht näher charakterisierte Plasmaproteine.

Inwieweit das Thyroxin für das Auftreten des $\beta$-HDL eine entscheidende Rolle spielt, werden noch laufende kontrollierte Stoffwechseluntersuchungen zeigen, die dazu bestimmt sind, qualitative und quantitative Versçhiebungen der einzelnen Plasmalipoproteinfraktionen unter Gabe von Thyroxin zu verfolgen.

Die geringe Verwertbarkeit einer isolierten Plasmacholesterinbestimmung zur Beurteilung einer Hyperthyreose wird verständlich durch die Tatsache, daß das Plasmacholesterin nicht nur von den $\beta$-Lipoproteinen mit dem höchsten Cholesteringehalt im Plasma transportiert wird, sondern von allen Plasmalipoproteinfraktionen.

Die Tatsache, daß sich das abnorme und hier erstmalig beschriebene $\beta$-HDL weder im Plasma gesunder Kontrollpersonen noch bei Patienten mit bisher charakterisierten Fettstoffwechselstörungen nachweisen läßt, eröffnet die Möglichkeit eines neuen differentialdiagnostischen Parameters der Hyperthyreose, dessen sichere Aussagekraft an einem größeren Patientengut zu prüfen sein wird.

Die Arbeit wurde durch Mittel der Deutschen Forschungsgemeinschaft und des Margarine-Instituts füt gesunde Ernährung unterstützt.

\section{Literatur}

1. Epstein, A. A. und H. Lande, Arch. Int. Med., Chicago 30, 563 (1917). - 2. Schally, A. O., Erg. inn. Med. 50, 480 (1936). 3. Hurxthal, A. R. und J. Hunt, Arch. Int. Med., Chicago 9, 717 (1935). - 4. SchettLER, G., Z. exper. Med. 115, 251 (1950). 5. SChetTler, G., Klin. Wschr. 28, 565 (1950). - 6. Schetrler, G. und H. Lukas, Z. inn. Med., Leipzig 6, 14 (1951). - 7. RoseMAN, R. H. und O. BYers, J. clin. Endocr., Springfield 12, 1287 (1952). - 8. Oberdisse, K. und E. Klein, Die Krankheiten der Schilddrüse. Georg Thieme Verlag, Stuttgatt (1967). - 9. HAGEN, J. H. und E. A. BALl, J. biol. Chemistry 235, 1545 (1960). 10. Hagen, J. H., J. biol. Chemistry 235, 2600 (1960). - 11. Rich, C., E. L. BiermanN und I. L. Schwartz, J. clin. Invest.
38, 275 (1959). - 12. MARCHI, P. und J. MAYER, Experiment 15, 359 (1959). - 13. Spirtes, M. A., G. Medes und S. Weinhouse, J. biol. Chemistry 204, 705 (1953). - 14. Debons, A. F. und I. L. Schwartz, J. Lipid Res. 4, 200 (1963). - 15. SEIDEL, D., In: Fettstoffwechselstörungen. Hrsg. Schettler, G. Georg Thieme Verlag, Stuttgart (1971). - 16. LeEs, R. S. und F. T. HATCH, J. Laborat. Clin. Med., S. Louis 61, 518 (1963). - 17. Greten, H. und D. Serdel, Dtsch. med. Wschr. 95, 1716 (1970). - 18. Burstein, M. und J. Samaille, Clin. Chim. Acta, Amsterdam 5, 609 (1960). - 19. Ouchterlony, O., Acta Pathol. Microbiol. Scand. 32, 231 (1953) - 20. Grabar, P. und C. A: Williams, Biochim. biophysica, Acta, Amsterdam 17, 67 (1955). - 21. 


\section{Sollen lhre Laboranten Listen schreiloer (ader Proben untersuchen?}

Unsere Lösung heißt: Direkte Probenidentifikation, on-lineMeßwerterfassung und real-time-Datenverarbeitung mit dem SILAB-System. Es bringt:

- Höhere Leistung des Labors durch sinnvolleren Einsatz der Fachkräfte bei wirtschaftlich optimaler Nutzung der Analysen und Meßgeräte.

- Termingerechte Analysen nach vielseitiger automatischer Kontrolle und sicherer Identifikation der Meßdaten.

- Arbeitsplatz- und patientenorientierte Zusammenstellung der automatisch verarbeiteten Daten. Ausgabe der Gesamtinformation in übersichtlichen, fehlerfreien Ergebnislisten.

Für weitere Informationen wenden Sie sich bitte an unsere nächstgelegene Geschäftsstelle oder an: SIEMENS AKTIENGESELLSCHAFT Med Dv · 8520 Erlangen - Postfach 400

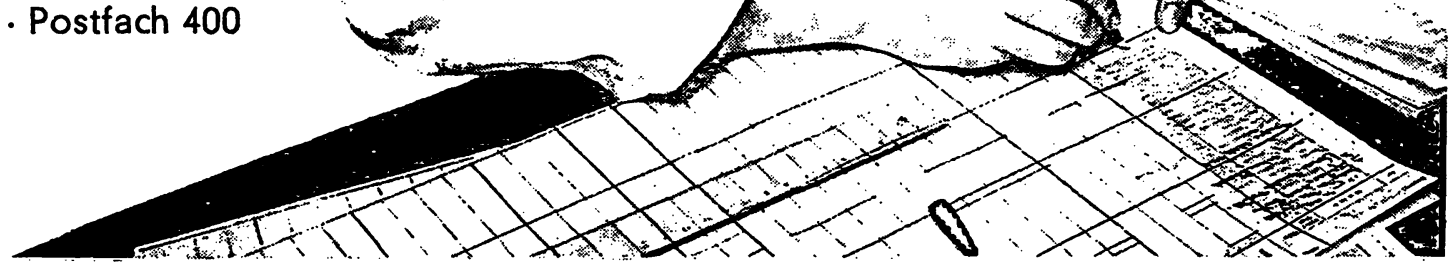

D)aten automatisch erfassen nnif dem SILAB-SyStern von Siemens 


\section{Er braucht kein Sprühkabinett Iüir die Đünn - schichr- Chromalographie.}

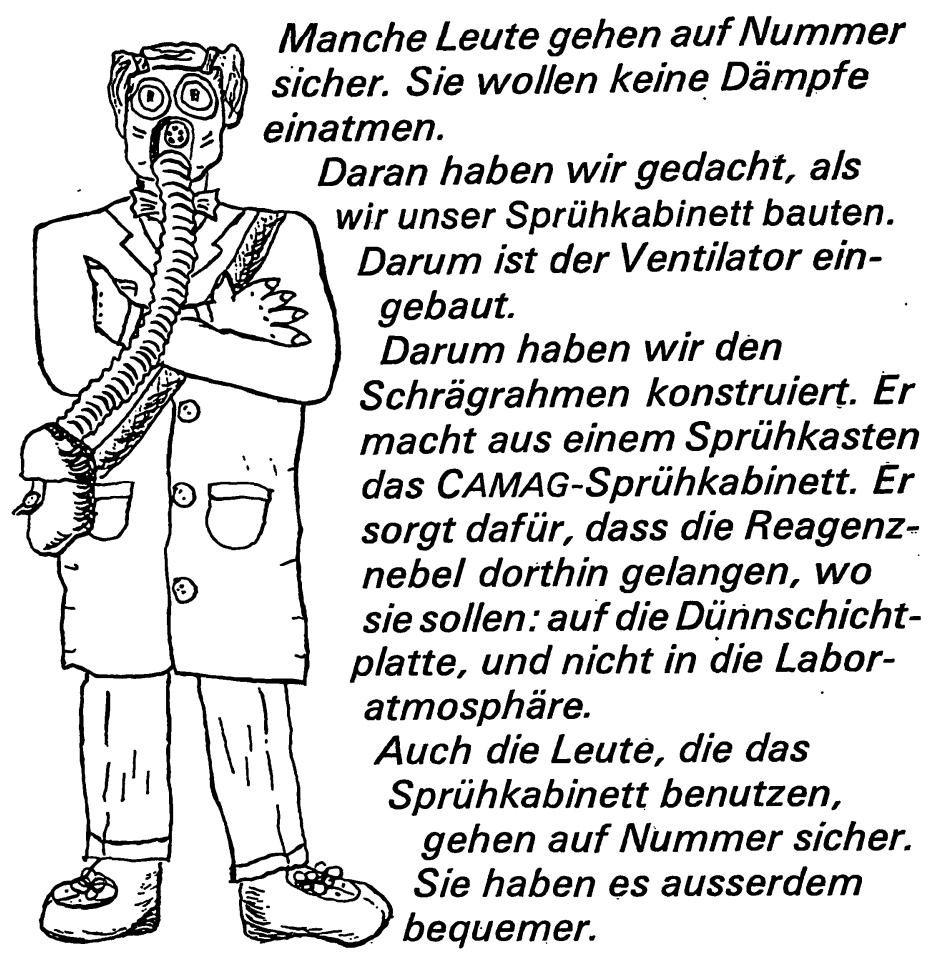

\section{und Sie?}

Kaufen Sie nun eine Gasmaske? Oder sollen wir Ihnen Unterlagen zum Sprühkabinett schicken?

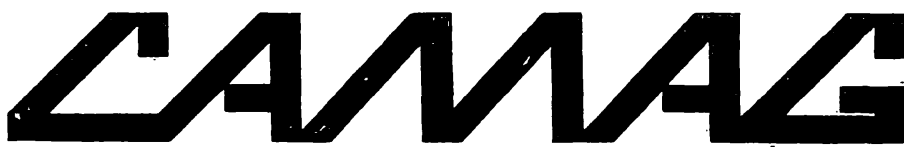

Führend in

Dünnschicht-Chromatographie Dünnschicht-Elektrophorese Hochspannungs-Elektrophorese

4132 Muttenz/Schweiz Homburgerstrasse 24

Tel. (061) 531430
1000 Berlin 41

Bismarckstrasse 27-29

Tel. (0311) 7915091
Praktische Berechnung der

Abschirmung von radioaktiver und Röntgen-Strahlung

Ausgangspunkt aller Schutzmaßnahmen sind Kenntnisse übe die physikalischen Eigenschaften der Materie und der Strah lung, die der Verfasser in den ersten Kapiteln behandelt. E folgt die Beschreibung von Wechselwirkungsprozessen de Röntgen- und Gamma-Strahlen, eine Zusammenfassung der in technischen Strahlenschutz am häufigsten verwendeten ra diologischen Größen und Einheiten unter Berücksichtigung de neuesten Bezeichnungen und Definitionen. Die Werkstoffe un Werkstoffdaten zur Abschirmung werden ebenso ausführlid behandelt, wie zeitsparende Berechnungsmethoden der Schutz vorrichtungen. Diese Berechnungen lassen sich mit geringsten Zeitaufwand anhand von speziellen Diagrammen, die die maß gebenden Strahlenschutzgrößen enthalten, durchführen. Weiter hin geht der Autor auf Probleme der Streustrahlung und au Temperaturberechnungen im Abschirmmaterial ein. Anhan praktischer Beispiele wird der Leser schließlich über möglich Strahlengefährdung und die entsprechenden Schutzmaßnahme. informiert.

Zur radioaktiven Strahlung zählen Alpha-, Beta- und Gamma Strahlen. Die Energie von Röntgen- und Gamma-Strahle gehört in der Medizin zu den wichtigsten therapeutische Agentien und diagnostischen Hilfsmitteln. Auch in viele naturwissenschaftlichen Disziplinen, besonders in der Physil Chemie, Medizin und Technik spielt die Anwendung vo Röntgen- und Gamma-Strahlen eine große Rolle. Durch di Anwendung der Kernenergie zur Stromerzeugung haben di Quellen energiereicher Gamma-Strahlung an Zahl und Grö!! erheblich zugenommen. Diese Strahlen sind aber nicht ung، fährlich.

Mit dem vorliegenden Buch, das keinerlei Spezialkenntnis voraussetzt, wird einem breiten Kreis Interessierter die Mö lichkeit gegeben, sich über Maßnahmen zum Schutz vor radi aktiven und Röntgen-Strahlen $\mathrm{zu}$ unterrichten. Das gilt $\mathrm{y}$ allem für Mediziner, Chemiker, Physiker, Architekten, Lab ranten, technische Assistenten und viele andere Mitarbeiter, d in kernphysikalischen, nuklearmedizinischen und radiochem schen Laboratorien, an Röntgen- und Gamma-Bestrahlung anlagen sowie in Kernkraftwerken und in der Kernbrennsto industrie tätig sind.

1972. Ca. 140 Seiten mit 101 Abbildungen und 12 Tabelle Format $21 \times 29,7 \mathrm{~cm}$. Leinen DM 64,-

Wir übersenden Ibnen gern unseren Sonderprospekt.

VERLAG CHEMIE GMBH WEINHEIM/BERGSTR. 
Seidel, D., P. Alaupovic und R. H. Furman, J. clin. Invest. 48, 124 (1969). - 22. Seidel, D., P. Alaupovic, R. H. Furman und W. J. McConathy, J. clin. Invest. 49, 2396 (1970). - 23. SeIdel, D., H. P. Geisen und H. Roelcke, FEBS-Letters 18, 43 (1971). - 24. Lowry, O. H., N. J. Rosebrough, A. L. FARR und R. J. Randall, J. biol. Chemistry 193, 265 (1951). - 25. Sperry, W. M. und M. WEBB, J. biol. Chemistry 187, 97 (1950). - 26. Gerlach, E. und B. Deuticke, Biochem. Z. 337, 477 (1963). 27. van Handel, E. und D. B. Zilversmit, J. Laborat. Clin. Med., S. Louis 50, 152 (1957). - 28. Davis, B. J., Ann. N. Y. Acad. Sci. 121, 404 (1964). - 29. Gray, W. R., Methods Enzvmol. 11, 139 (1967). - 30. Scane, A. L., A. Lewis und F. M. Bumpus, Arch. Biochem. Biophysics 74, 390 (1958). - 31. SCANu, A. L., J. biol. Chemistry 242, 711 (1967). - 32. De Lalla, L., L. Levine und R. K. Brown, J. exper. Med. 106, 261 (1957). 33. LEVY, R. I. und D. S. FredRICKSON, J. clin. Invest. 44, 426 (1965). - 34. ScanU, A., J. Lipid Res. 7, 295 (1966). - 35. SHORE, B. und V. SHORE, Biochemistry, USA 7, 2773 (1968). 36. Berg, K., Acta Path. Microbiol. Scand. 59, 369 (1963). -
37. Nicногs, A. V., Proc. nat. Acad. Sci. (Wash.) 64, 1128 (1969). 38. Gopman, J. W., O. De Lalia, F. Glazier, N. K. Freeman, F. T. Lindgren, A. V. Nichols, B. Strisower und A. R. Tamplin, Plasma 2, 413 (1954). - 39. Strisower, B., P. Elmlinger, J. W. Gofman, N. D. De Lalla und O. De Lalia, J. clin. Endocr., Springfield 19, 117 (1959). - 40. Furman, R. H., R. P. Howard und K. Lakshmi, Amer. J. Clin. Nutr. 9, 73 (1961). 41. Seider, D., B. Agostins und P. Müller, Biochim. biophysica Acta, Amsterdam 260, 146 (1972). - 42. TAtA, J. R., Nature, London 219, 331 (1968). - 43. TATA, J. R., Proc. soc. int. Congr. of Endocr., London Part 1, 46 (1964). - 44. Sokoloff, L., Proc. soc. int. Congr. of Endocr., London Part 1, 87 (1964). 45. Adams, D. D., J. clin. Endocr., Springfield 18, 699 (1958). 46. Brunke, G., J. clin. Endocr., Springfield 27, 1161 (1967). 47. Schemmel, K. und L. Weisbecker, Erg. inn. Med. 29, 278 (1970). - 48. MCKENzIE, J. M., J. clin. Endocr., Springfield 25, 424 (1965). - 49. Cilopra, I. J., G. N. Beall und D. H. SoloMON, J. clin. Endocr., Springfield 32, 772 (1971).

Priv.-Doz. Dr. Dietrich Scidel

Chemisches Laboratorium, Med. Universitätsklinik 69 Heidelberg

Bergheimerstr. 58

Germany 